\title{
ESTRUTURA E COMPOSIÇÃO DA ICTIOFAUNA DE RIACHOS DO RIO PARANAPANEMA, SUDESTE E SUL DO BRASIL
}

\author{
Ricardo M. C. Castro ${ }^{1}$; Lilian Casatti ${ }^{2}$; Hertz F. Santos ${ }^{1}$; Katiane M. Ferreira ${ }^{1}$; Alexandre C. Ribeiro ${ }^{1}$; Ricardo C. \\ Benine $^{1}$; Gabriela Z. P. Dardis ${ }^{1}$; Alex L. A. Melo ${ }^{1}$; Renata Stopiglia ${ }^{1}$; Tatiana X. Abreu ${ }^{1}$; Flávio A. Bockmann ${ }^{1}$; \\ Murilo Carvalho ${ }^{1}$; Fernando Z. Gibran ${ }^{1}$ \& Flávio C. T. Lima ${ }^{3}$
}

\author{
Biota Neotropica v3 (n1) -http://www.biotaneotropica.org.br/v3n1/pt/abstract?article+BN01703012003 \\ Recebido em: 18/02/2003 \\ Publicado em: 11/04/2003
}

\begin{abstract}
${ }^{1}$ Laboratório de Ictiologia de Ribeirão Preto (LIRP), Departamento de Biologia da FFCLRP-USP (www.ffclrp.usp.br), Av. Bandeirantes 3900, 14040-901, Ribeirão Preto, SP, Brasil

${ }^{2}$ Departamento de Zoologia e Botânica, IBILCE, Universidade Estadual Paulista (www.ibilce.unesp.br), R. Cristóvão Colombo 2265, 15054-000, São José do Rio Preto, SP, Brasil
\end{abstract}

\author{
${ }^{3}$ Museu de Zoologia da Universidade de São Paulo, MZUSP (www.mz.usp.br), Caixa Postal 42594, 04299-970, São Paulo, \\ SP, Brasil \\ Autor para correspondência: Ricardo M. C. Castro (e-mail: rmcastro@ ffclrp.usp.br)
}

\begin{abstract}
Seventeen $100 \mathrm{~m}$ long streams stretches, none of an order higher than three, were sampled to both sides of the main channel of Rio Paranapanema in the States of São Paulo and Paraná, southeastern and southern Brazil. Each stream stretch had its midpoint located with a GPS satellite receiver and had its fish fauna sampled via a standardized environmental data and fish collection methodology (primarily utilizing electrofishing) with the aim of providing the following information about each stream: 1) the taxonomic composition of the fish fauna and the contribution of each species in that stream in terms of both number of individuals and biomass; 2) a photographic documentation of the live coloration of representative specimens of each collected species; and 3) the description of each sampled environment, with colored photographic illustrations and details of the main biotic and abiotic parameters. Overall 3,683 fishes were collected, belonging to six orders, 16 families, 37 genera, and 52 species, with a total biomass of $16.8 \mathrm{~kg}$. Of the collected species, approximately $36 \%$ were Siluriformes, $36 \%$ Characiformes, $11 \%$ Gymnotiformes, $10 \%$ Perciformes, $4 \%$ Cyprinodontiformes, and $2 \%$ Synbranchiformes. The most abundant species in terms of total number of individuals were Astyanax altiparanae (15.2\%) and Astyanax sp. 1 (12.3\%); The species with the largest biomasses were Astyanax altiparanae (28\%) and Geophagus brasiliensis (13\%). In terms of abundance and biomass collected for each family, the Characidae was clearly the predominant family followed by the Loricariidae, Pimelodidae, and Cichlidae. Among the sampled stream stretches, locality 14 with 24 species and locality 13 with five species yielded the highest and lowest richness in terms of species numbers, respectively. This coincides with the values obtained for the Shannon-Wienner index of specific diversity $\left(\mathrm{H}^{\prime}=0.99\right.$ and 0.32 , respectively). The median species richness for all streams stretches was 11 . In the species richness estimate by extrapolation for all 17 sampled stream stretches, a value of 69 species was obtained (with a standard error of four) indicating the need for an additional moderate sampling effort to reach the asymptote of the curve. Of the 52 collected species, eight (approximately $15 \%$ of the total) are clearly new to science and five other species (approximately $10 \%$ of the total) are of indefinite taxonomic status and require further analysis. Three of the captured species are introduced (approximately $6 \%$ of the total). Analysis of the trophic and spatial structure of the studied fish fauna indicates that the 10 numerically dominant species in the sampled streams can be grouped into four guilds that are in decreasing order of numeric importance: nektonic omnivores; benthonic invertivores; periphytovores; and benthonic omnivores. An identification key for all the species of fish collected during this study it is provided.
\end{abstract}

Key words: Upper Rio Paraná basin, Rio Paranapanema, stream fishes, diversity, southeastern and southern Brazil. 


\section{Resumo}

Foram amostrados 17 trechos de riachos com $100 \mathrm{~m}$ de extensão, todos de ordem igual ou menor a três, ao longo de ambas as margens do canal principal do Rio Paranapanema, SP e PR. O ponto médio de cada trecho foi georreferenciado via satélite com receptor GPS e o uso de metodologia padronizada de coleta de dados ambientais e peixes (baseada principalmente na pesca elétrica), possibilitou a obtenção das seguintes informações em cada local: 1) composição taxonômica da ictiofauna e contribuição, em termos de número de indivíduos e biomassa, de cada espécie para a ictiofauna local como um todo; 2) documentação fotográfica de espécimes representativos de cada espécie coletada com sua coloração natural; 3) descrição de cada ambiente coletado, com ilustrações fotográficas coloridas, e seus principais parâmetros bióticos e abióticos. No total foram coletados 3.683 exemplares, pertencentes a seis ordens, 16 famílias, 37 gêneros e 52 espécies, com biomassa total de $16,8 \mathrm{~kg}$. Das espécies coletadas, aproximadamente $36 \%$ pertencem a ordem Siluriformes, $36 \%$ a Characiformes, $11 \%$ a Gymnotiformes, $10 \%$ a Perciformes, $4 \%$ a Cyprinodontiformes e 2\% a Synbranchiformes. As espécies mais abundantes em termos de número de indivíduos foram Astyanax altiparanae $(15,2 \%)$ e Astyanax sp. 1 (12,3\%); aquelas com maior biomassa foram A. altiparanae (28\%) e Geophagus brasiliensis (13\%). A composição da ictiocenose em termos de abundância e biomassa por família indica a predominância expressiva de Characidae, seguida por Loricariidae, Pimelodidae e Cichlidae. Dentre os trechos amostrados, o trecho 14 (24 espécies) e o 13 (cinco espécies), apresentaram a maior e a menor riqueza em espécies, respectivamente, coincidindo com os valores obtidos para o índice de diversidade específica de Shannon-Wienner $\left(\mathrm{H}^{\prime}=\right.$ 0,99 e 0,32 , respectivamente). A riqueza média encontrada foi de 11 espécies por trecho de riacho. Na estimativa de riqueza por extrapolação para o conjunto total de riachos amostrados na bacia do rio Paranapanema, obtivemos um valor de 69 espécies (erro padrão igual a quatro) indicando ser necessário um esforço amostral adicional moderado para atingir a assíntota da curva. Das 52 espécies coletadas, oito (aproximadamente 15\% do total) são seguramente novas, cinco (aproximadamente 10\% do total) possuem "status" taxonômico ainda indefinido, enquanto outras três (aproximadamente 6\% do total) são espécies introduzidas. Analisando a estrutura trófica e espacial da ictiocenose estudada, as 10 espécies numericamente dominantes nos riachos estudados dividem-se, em ordem decrescente de importância numérica, em quatro guildas: onívoros nectônicos; invertívoros bentônicos; perifitívoros; e onívoros bentônicos. Uma chave de identificação para todas as espécies de peixes coletadas durante este estudo é fornecida ao final deste trabalho.

Palavras-chave: Bacia do Alto Rio Paraná, Rio Paranapanema, peixes de riacho, diversidade, sudeste e sul do Brasil.

\section{Introdução}

O sistema do Alto Rio Paraná (Figura 1) pertence à região ictiofaunística do Paraná (Géry, 1969) - que inclui o sistema dos Rios da Prata-Uruguai-Paraná-Paraguai, e representa o segundo maior sistema de drenagem na América do Sul, com 3,2 milhões de km² (Lowe-McConnell, 1987, 1999). Corresponde à porção da bacia do Rio Paraná situada a montante de Sete Quedas (agora inundada pelo Reservatório de Itaipu), abrigando grandes tributários como os Rios Grande, Paranaíba, Tietê e Paranapanema.

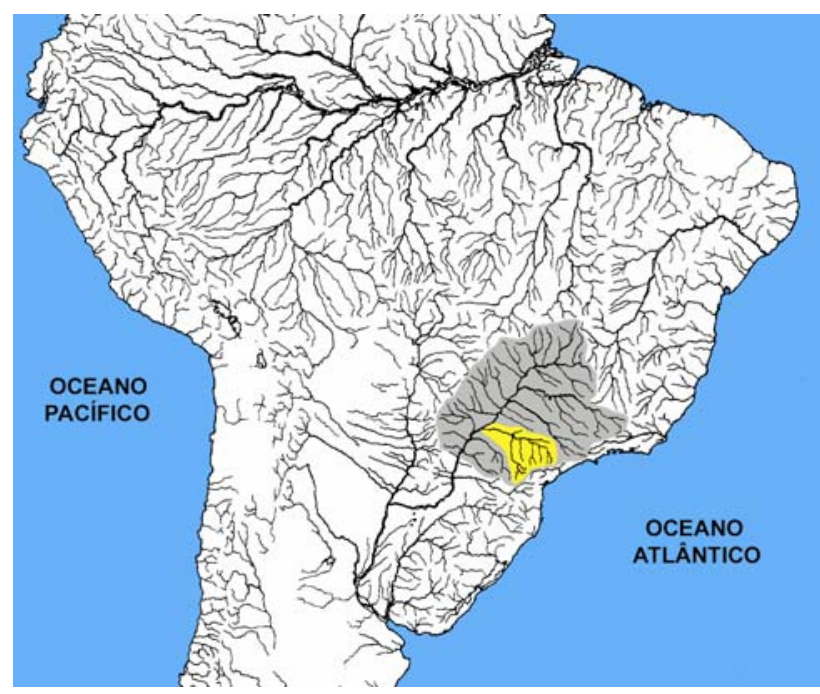

Figura 1. Principais drenagens da América do Sul com a bacia do Alto Rio Paraná (em cinza) e sub-bacia do Rio Paranapanema (em amarelo) salientadas.

A drenagem do Alto Rio Paraná possui aproximadamente $900.000 \mathrm{~km}^{2}$, incluindo o norte do Estado do Paraná, sul do Mato Grosso do Sul, a maioria do Estado de São Paulo (a oeste da Serra do Mar), sul de Minas Gerais, sul de Goiás e uma área pequena do Paraguai oriental adjacente ao Mato Grosso do Sul. A área como um todo localiza-se na face sul do Escudo Brasileiro e inclui frações dos domínios morfoclimáticos dos Cerrados, Planaltos de Araucárias, e Tropical Úmido, bem como as regiões de transição correspondentes entre eles (Ab’Sáber, 1977a, 1977b). Quanto à fitogeografia, a região abrange áreas pertencentes às províncias Atlântica e Central (Rizzini, 1997), com vegetação caracterizada por Florestas Subtropicais Decíduas e Mesofíticas (=Florestas Estacionais Deciduais e Semideciduais), Cerrados, Florestas de Araucárias (=Floresta Ombrófila Mista), Campos Rupestres e Matas de Galeria (=Comunidades Aluviais) (Hueck \& Seibert, 1981). Há evidências fortes de que, pelo menos com relação a alguns grupos de peixes, o Alto Rio Paraná constitua uma área de endemismo, causalmente conectada à formidável barreira para os peixes migradores representada, até recentemente, por Sete Quedas, que isolou por muito tempo a maioria da ictiofauna do Alto Rio Paraná da fauna remanescente dos sistemas dos rios da Prata-Uruguai- 
Paraná-Paraguai (ver Britski \& Langeani, 1988; Menezes, 1988; Vari, 1988; Weitzman et al., 1988; Langeani, 1990; Menezes, 1996a, 1996b; Castro \& Casatti, 1997).

No Estado de São Paulo, de acordo com Castro \& Menezes (1998), o sistema do Alto Paraná inclui os maiores rios do Estado e contém 22 famílias e aproximadamente 170 espécies de peixes descritas. Estes grandes canais principais são habitados por espécies de médio a grande porte, como os curimbatás (Prochilodus spp.), piaparas (Leporinus spp.), pintados (Pseudoplatystoma spp.) e jaús (Zungaro zungaro), normalmente com distribuições geográficas extensas e importância na pesca comercial e de subsistência. Associado a estes grandes rios há um grande número de riachos e cabeceiras, habitados principalmente por espécies de peixes de pequeno porte (geralmente menos que $15 \mathrm{~cm}$ de comprimento padrão), com distribuições geográficas restritas, pouco ou nenhum valor comercial e muito dependentes da vegetação ripária para alimentação, abrigo e reprodução (ver Böhlke et al., 1978; Lowe-McConnell, 1987, 1999). Espécies de peixes de pequeno porte correspondem a aproximadamente $50 \%$ do total de espécies de peixes de água doce descritas da América do Sul e mostram um grau elevado de endemismo. O estudo da sistemática, evolução e biologia geral das espécies de peixes de pequeno porte é, sem dúvida, o grande desafio da ictiologia sul-americana no início deste século (Castro \& Menezes, 1998; Castro, 1999). Infelizmente, tais espécies, por serem fortemente dependentes do material orgânico alóctone importado da vegetação marginal para sobreviver (ver Lowe-McConnell, 1975, 1987, 1999; Menezes et al., 1990; Sabino \& Castro, 1990; Araújo Lima et al., 1995), também estão ameaçadas por atividades antrópicas prejudiciais como o desmatamento e uso de fertilizantes e praguicidas associados a atividades agrícolas intensivas.

Estimativas feitas durante a reunião do Grupo de Trabalho "Bacias Hidrográficas", no Workshop do Programa BIOTASP/FAPESP "Bases para a conservação da biodiversidade do Estado de São Paulo”, Serra Negra, SP, Brasil, 30 de julho a 02 de agosto de 1997, indicam que no Estado de São Paulo, dentro do sistema do Alto Paraná, as sub-bacias (= Unidades de Gerenciamento de Recursos Hídricos - UGRHI, do Plano de Gerenciamento Hídrico de São Paulo, 1996) do Pontal do Paranapanema, Alto Paranapanema, Peixe, Aguapeí, Baixo Tietê e São José dos Dourados, são pobremente amostradas. As sub-bacias do Médio Paranapanema, Turvo-Grande, Baixo Pardo-Grande, Sapucaí-Grande e Piracicaba-Capivari-Jundiaí são moderadamente amostradas, e somente as sub-bacias do Tietê-Sorocaba, Tietê-Jacareí, Tietê-Batalha, Mogi-Guaçu e Pardo são razoavelmente amostradas. Isso significa que, em relação à ictiofauna, aproximadamente $70 \%$ das sub-bacias de drenagem do Alto Rio Paraná no Estado de São Paulo não foram ainda exploradas satisfatoriamente em termos científicos.
Sendo assim, dentro dos objetivos gerais do Programa BIOTA/FAPESP - O Instituto Virtual da Biodiversidade (www.biota.org.br), o Projeto Temático "Diversidade de peixes de riachos e cabeceiras da bacia do Alto Rio Paraná no Estado de São Paulo, Brasil" (www.bdt.fat.org.br/peixes_pr/), tem como objetivo principal o estudo da fração menos conhecida, maior e mais ameaçada da diversidade de peixes do Estado de São Paulo. Este objetivo foi atingido através da aplicação de uma metodologia padronizada de coleta de dados ambientais e de peixes em cada trecho de riacho amostrado, que possibilitou a obtenção do seguinte conjunto de dados: 1) composição taxonômica da ictiofauna e contribuição, em termos de número de indivíduos e biomassa, de cada espécie para a ictiofauna local como um todo; 2) documentação fotográfica de espécimes representativos de cada espécie coletada com sua coloração natural; 3) descrição de cada ambiente coletado, com ilustrações fotográficas coloridas e seus principais parâmetros bióticos e abióticos. Esperamos que os dados assim obtidos, além de fornecer um retrato instantâneo e testemunho duradouro de cada trecho de riacho no momento de sua amostragem, possam servir também para subsidiar futuros estudos sobre a conservação e manejo de ambientes desse tipo no Estado de São Paulo e no restante do país.

Este trabalho, referente à totalidade da bacia do Rio Paranapanema, é o primeiro de uma série de três trabalhos de natureza sintética descritiva, apresentando os dados obtidos por nosso Projeto Temático agrupados por grande unidades hidrográficas/geográficas.

\section{Caracterização da área geral de estudo}

O Rio Paranapanema (Figuras 1 e 2) nasce na Serra de Paranapiacaba (48ำ $15^{\prime} \mathrm{W} 24^{\circ} 16^{\prime}$ 'S), a aproximadamente $900 \mathrm{~m}$ de altitude, e deságua no Rio Paraná após percorrer cerca de $500 \mathrm{~km}$ e receber como tributários principais os Rios Itararé, Pardo, Tibagi e Pirapó (Ziesler \& Ardizzone, 1979), fazendo a maior parte da fronteira entre os Estados de São Paulo e Paraná. Sua bacia de drenagem possui aproximadamente $109.600 \mathrm{~km}^{2}$ (Sampaio, 1944), estendendose por três grandes unidades do relevo brasileiro: o Planalto Atlântico, a Depressão Periférica e o Planalto Arenítico Basáltico Ocidental (Ab'Saber, 1956). A Serra de Paranapiacaba, onde situa-se sua nascente, constitui o divisor de águas das bacias pequenas voltadas para a costa, do Ribeira de Iguape, do Paraíba do Sul e do Paraná, com altitudes de até $1.100 \mathrm{~m}$ e afloramentos de rochas précambrianas constitutivas. Deixando a serra, os afluentes da margem direita da bacia do Rio Paranapanema seguem por uma faixa de terrenos sedimentares carbonífero-permianos dos grupos Itararé e Passa Dois e, a partir das proximidades da cidade de Piraju, correm pelo grande domínio dos derramamentos basálticos do final do Mesozóico, a chamada formação Serra Geral. Em seu trecho final, das proximidades 


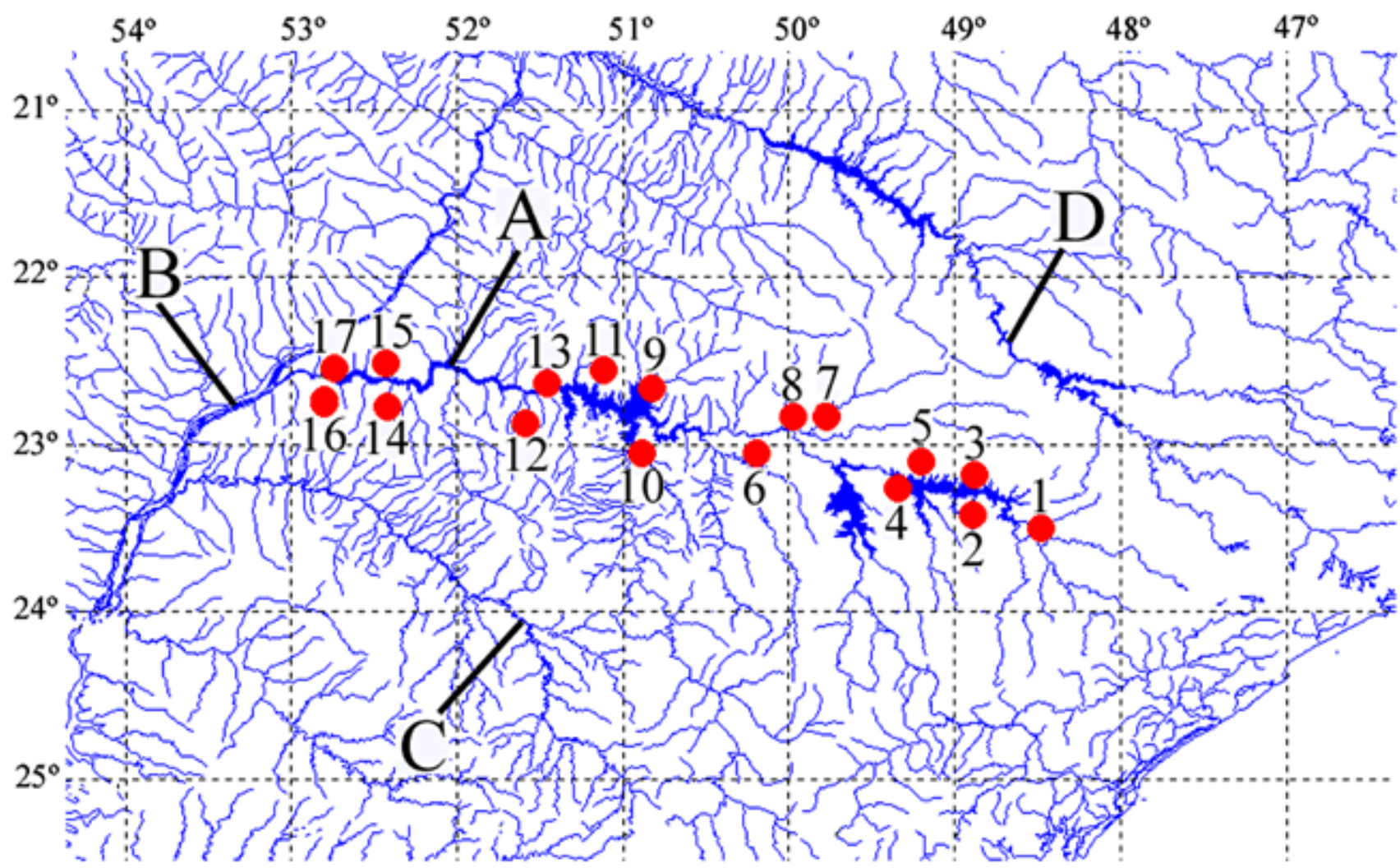

Figura 2. Localização dos 17 trechos de riacho amostrados na bacia do Rio Paranapanema: A) Rio Paranapanema, B) Rio Paraná; C) Rio Ivaí; D) Rio Tietê.

da cidade de Teodoro Sampaio até seu encontro com o rio Paraná, drena os sedimentos cretáceos da formação Caiuá (Instituto Geográfico e Geológico, 1974).

O clima geral nas porções superior e média da bacia é tropical subquente e superúmido, com subseca, enquanto que na porção inferior é tropical subquente úmido, com um a dois meses secos. De modo geral, há pelo menos um mês por ano com temperatura média inferior a $18^{\circ} \mathrm{C}$ e a temperatura média no mês mais quente é superior a $22^{\circ} \mathrm{C}$. A maior parte da bacia está inclusa nas isoietas de $1.200 \mathrm{~mm}$ anuais (Nimer, 1989). No passado recente, em tempos históricos, a área da bacia de drenagem do Rio Paranapanema era majoritariamente coberta pelos Bosques Subtropicais Decíduos e Mesofíticos do Brasil Oriental e Meridional (=Floresta Estacional Semidecidual) (Huek \& Seibert, 1981). Sua ictiofauna, até o momento, foi pouco ou nada estudada, sendo os poucos trabalhos efetivamente publicados - com exceção de Henry et al. (1994), Uieda et al. (1997), Casatti et al. (2001) e Casatti (2002), lidando com a fauna de riachos - limitados à fauna de porte médio a grande sobrevivente nos reservatórios (p. ex. Carvalho et al., 1998). Infelizmente, do ponto de vista ambiental, o Rio Paranapanema foi bastante impactado pela ação antrópica relativamente recente. Seu canal principal atualmente consiste de uma sucessão de barragens (UHEs Jurumirim, Chavantes, Salto Grande, Canoas II, Canoas I, Capivara, Taquaruçu e Rosana), com uma potência total instalada de $2.304 \mathrm{MW}$, alagando aproximadamente $1.800 \mathrm{~km}^{2}$ de sua bacia de drenagem (www.dukeenergy.com.br/pt/links.asp, 08.ix.2001). Da vegetação original da área estudada aqui, praticamente nada sobrou, sendo os Parques Estaduais de Intervales e Morro do Diabo (Inventário Florestal do Estado de São Paulo, 1993), os únicos fragmentos contínuos de floresta com porte significativo, sendo a área desmatada convertida primariamente a atividades agropecuárias (ver Figura 3). É importante apontar que somente dois trechos de riachos coletados corriam dentro de fragmentos significativos de vegetação nativa. Todos os demais corriam inseridos em matas ciliares geralmente estreitas e degradadas em graus 


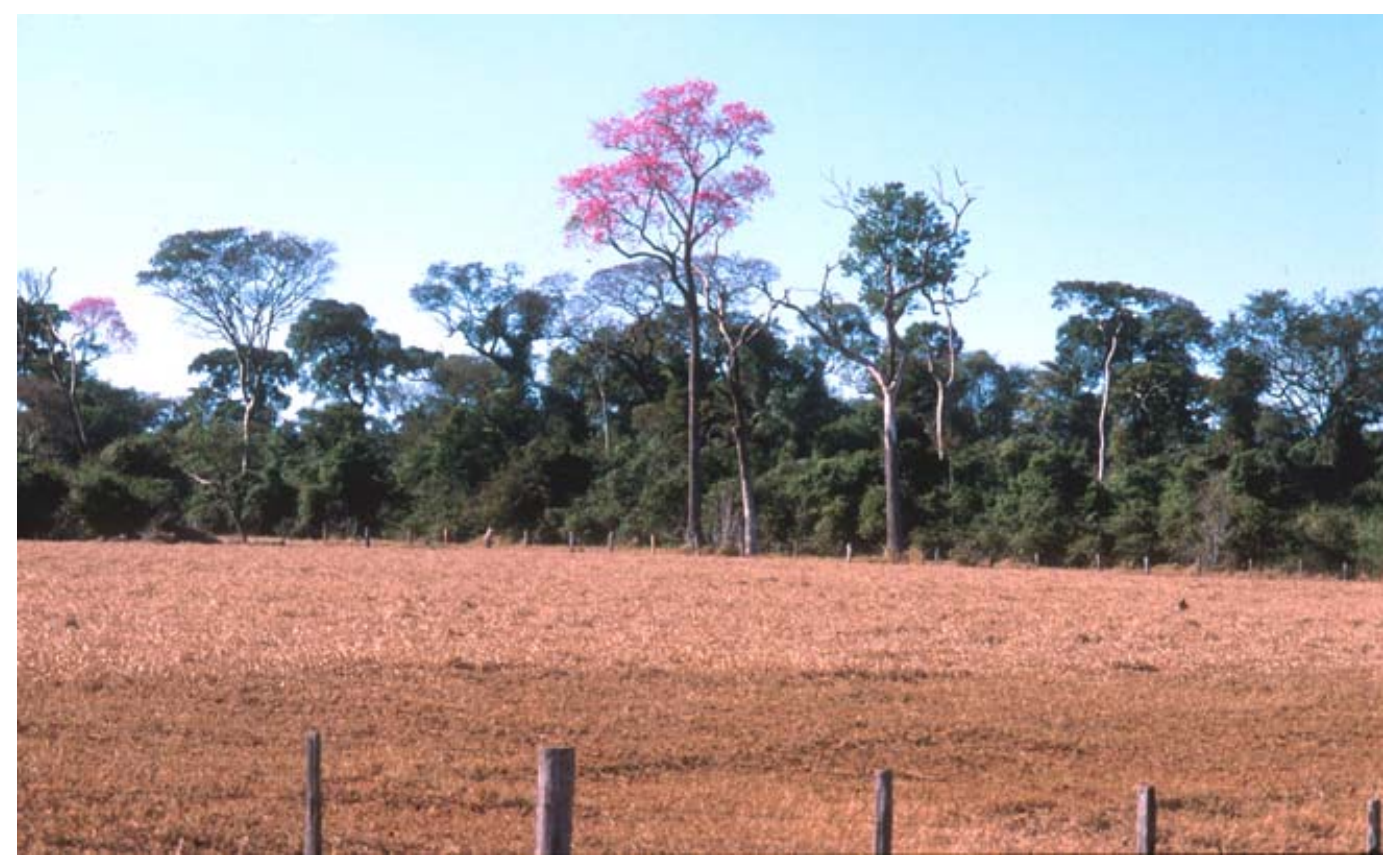

Figura 3. Vista de seção da borda leste do Parque Estadual Morro do Diabo, Município de Teodoro Sampaio, SP, maior fragmento paulista remanescente de Floresta Estacional Semidecidual, mostrando o profundo impacto de um dos tipos de desmatamento mais comuns na bacia do Rio Paranapanema: áreas de pastagem. (Foto Ricardo M. C. Castro).

variáveis, totalmente cercadas ou por áreas de pastagem ou de cultivo.

\section{Material e métodos}

\subsection{Desenho amostral}

Os 17 trechos de riachos amostrados, cada um com aproximadamente $100 \mathrm{~m}$ de extensão (Figura 2), foram escolhidos de tal forma que a distância entre eles fosse, na medida do possível, eqüidistante, ao longo de ambas as margens do canal principal do Rio Paranapanema, sendo sete na margem esquerda e 10 na direita. A definição de riacho adotada é aquela proposta por Castro (1999), e todos os trechos eram de ordem igual ou menor a três (cf. Strahler, 1957). O ponto médio de cada trecho foi georreferenciado via satélite com receptor GPS (Garmin III); as informações sobre os municípios, altitudes e ordens dos trechos de riacho amostrados foram extraídas de cartas 1:50.000 do IBGE e IGGSP.

\subsection{Coleta de dados ambientais}

A informação geral de campo sobre cada trecho de riacho foi padronizada, quando cabível, de acordo com o modelo apresentado nas fichas de coleta do Programa BIOTA/FAPESP (ver www.biota.org.br). A documentação fotográfica do ambiente foi feita com uma câmera SLR 35 $\mathrm{mm}$, utilizando-se um tripé de suporte posicionado no meio do canal no ponto médio do trecho de riacho.

Os dados de mensuração física do ambiente foram tomados com trena e a velocidade da corrente estimada pelo método do objeto flutuante (Brower \& Zar, 1984). A transparência horizontal da água foi estimada através de disco de Secchi iluminado por lanterna estanque e observado por um membro da equipe equipado com um periscópio estanque, até seu desaparecimento. Nas imediações do ponto médio de cada trecho, foi coletada uma amostra de aproximadamente $500 \mathrm{ml}$ do substrato superficial do leito para análise granulométrica. As medidas de temperaturas do ar e da água, $\mathrm{pH}$, oxigênio dissolvido e condutividade foram tomadas com equipamentos digitais portáteis. Amostras das espécies de plantas mais abundantes no local e com algum contato com a água foram coletadas, herborizadas e identificadas até o nível taxonômico possível.

\subsection{Coleta e fotografia de peixes}

Para a coleta de peixes, em cada trecho de $100 \mathrm{~m}$ de riacho, foi aplicada uma combinação de diversos métodos de captura (Figura 4) de forma a ser obtida uma amostra a mais próxima possível da totalidade da ictiofauna presente em cada trecho amostrado. Assim sendo, o esforço de coleta aplicado a cada variante metodológica foi tão padronizado quanto possível. Com exceção da pesca elétrica, os demais métodos citados estão detalhadamente explicados em Vanzolini \& Papavero (1967) e Malabarba \& Reis (1987). O método de pesca elétrica utilizado baseou-se em Reynolds (1992), Severi et al. (1995), Suzuki et al. (1997), Mazzoni et al. (2000) e Sônia Buck (comunicação pessoal), com modificações. O equipamento utilizado é ilustrado na Figura 4.1. 

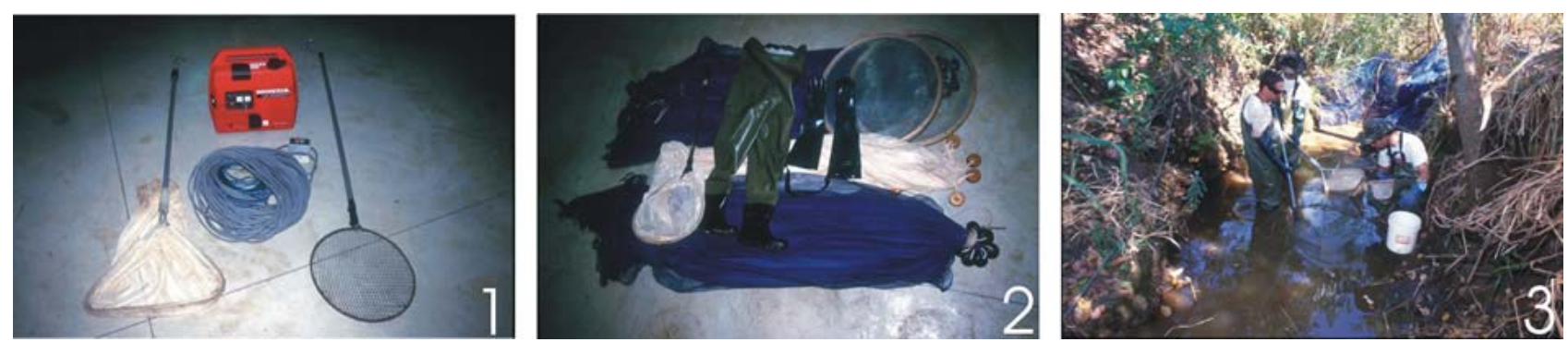

Figura 4. Materiais e aplicação de métodos de coleta de peixes: 1) vista geral do equipamento utilizado para pesca elétrica: gerador portátil de corrente alternada (centro, acima), cabo de conexão entre o gerador e os eletrodos (centro abaixo), com interruptor de segurança, puçá condutor (esquerda) e eletrodo em forma de espátula, formado por rede metálica (direita); 2) vista geral dos equipamentos de pesca: duas redes de bloqueio (acima e abaixo, azul-escuras), puçá não condutor para auxiliar na pesca elétrica (esquerda, com malha branca), rede de arrasto manual (direita, com bóias de cor bege), peneiras metálicas (canto superior esquerdo), luvas e macacões plásticos para isolamento elétrico (centro, orientados verticalmente); 3) equipe de coleta preparando-se para iniciar a passagem de pesca elétrica; os dois coletores do lado esquerdo da foto portam os eletrodos e o do lado direito, um balde com água e um puçá simples, não condutor (Fotos Ricardo M. C. Castro).

Cada trecho de $100 \mathrm{~m}$ de riacho foi bloqueado em seus extremos com redes de bloqueio $(10 \times 2 \mathrm{~m}, 5 \mathrm{~mm}$ de malha) para impedir a fuga dos peixes. Foram feitas coletas sucessivas (sentido jusante-montante), com duração aproximada de 30 minutos cada, três delas por pesca elétrica (Figura 4), duas com uma rede de arrasto manual (3,5 x 1,7 m, $5 \mathrm{~mm}$ de malha) e uma com peneiras metálicas $(75 \mathrm{~cm}$ de diâmetro, 2 mm de malha) (Figura 4.2). As passagens com arrastos manuais e peneiras foram intercaladas, sem paradas, entre as passagens de pesca elétrica. Na pesca elétrica, dois coletores equipados com eletrodos foram seguidos por um coletor equipado com um puçá simples e um balde, para auxiliar na coleta dos peixes afetados pela corrente elétrica, porém não capturados pelo operador com o puçá condutor (Figura 4.3).

O principal componente do equipamento de pesca elétrica (Figura 4.1) utilizado neste estudo é um gerador portátil de corrente alternada $(220 \mathrm{~V}, 50-60 \mathrm{~Hz}, 3,4-4,1 \mathrm{~A}$, $1000 \mathrm{~W}$ ), ligado a dois eletrodos por um cabo multifilamento flexível com 60 metros de extensão. O eletrodo em forma de espátula gradeada é feito de aço inoxidável $(40 \mathrm{~cm}$ de diâmetro, $10 \mathrm{~mm}$ de malha); o eletrodo de captura propriamente dito é um puçá triangular $(40 \times 25 \times 15 \mathrm{~cm}) \mathrm{com}$ armação de alumínio e um saco de rede com $50 \mathrm{~cm}$ de profundidade (1,5 mm de malha). Ambos ligam-se ao cabo principal por um fio condutor de $1,5 \mathrm{~mm}$ de diâmetro. Por motivos de segurança, na empunhadura do puçá há um botão interruptor que só permite a passagem de corrente quando pressionado; em adição, há também uma chave trifásica no cabo principal a dois metros do gerador. Os coletores sempre trajavam macacões e luvas eletricamente isolantes (Figuras 4.2 e 4.3).

Todos os exemplares capturados, com exceção daqueles selecionados para fotografia e/ou para extração de amostras de tecido para análises genéticas foram imediatamente fixados em formalina $10 \%$, transferidos para etanol $70 \%$ para conservação e depositados na coleção do Laboratório de Ictiologia de Ribeirão Preto (LIRP), do
Departamento de Biologia da F.F.C.L.R.P. - Universidade de São Paulo (ver item de número sete deste trabalho). O material coletado foi separado em lotes mono-específicos, e os indivíduos de cada lote foram contados, medidos (comprimento padrão em mm) e pesados (gr). Para ilustração fotográfica das espécies de peixes coletadas, alguns exemplares foram fotografados vivos, no campo, em vista lateral esquerda, imersos em água, em um pequeno aquário de vidro.

\subsection{Tratamento e análise dos dados}

A diversidade de espécies foi medida através dos índices de diversidade específica de Shannon-Wiener ( $\mathrm{H}^{\prime}=$ - $\Sigma \mathrm{p}_{\mathrm{i}} \cdot \ln \mathrm{p}_{\mathrm{i}}$, onde pé a frequiência relativa da espécie i) e de Simpson $\left(\mathrm{D}=\Sigma \mathrm{p}_{\mathrm{i}}{ }^{2}\right.$ ) e a uniformidade da distribuição das espécies foi medida através do índice de equitabilidade ( $\mathrm{E}=$ H'/Hmax) (cf. Ludwig \& Reynolds, 1988). Tais análises foram conduzidas com o auxílio do programa de computador Bio Diversity Pro (McAlecce et al., 1997).

Para avaliar a eficiência do inventário, foi utilizado um estimador de riqueza por extrapolação ("Incidence-based Coverage Estimator", ICE, cf. Lee \& Chao, 1994), que possibilita o cálculo do fator de correção utilizando a incidência (freqüência de ocorrência) de espécies raras. Este procedimento foi realizado com o auxílio do pacote estatístico para PC EstimateS 5, aplicando-se a opção de 50 aleatorizações (Colwell, 1997).

\section{Resultados}

São apresentados os dados de posição geográfica, altitude, hierarquia fluvial (ordem) de todos os trechos de riacho e datas de coleta (Tabela 1); fisiografia, parâmetros físico-químicos, transparência horizontal da água, granulometria predominante do fundo, tipo da vegetação do entorno (Tabela 2) e descrições gerais sucinta de cada trecho (Tabela 3). Nas Figuras 5.1 a 5.17, o ponto médio de cada trecho é ilustrado. 
Tabela 1. Localização, altitude, hierarquia fluvial (ordem) e data de coleta dos trechos de riachos amostrados na bacia do Rio Paranapanema.

\begin{tabular}{|c|c|c|c|c|c|}
\hline Trechos & Estado & Localidade & $\begin{array}{c}\text { Altitude } \\
(\mathbf{m})\end{array}$ & Ordem & Data \\
\hline 1 & SP & $\begin{array}{l}\text { Município de Angatuba, Córrego Poço dos Patos } \\
\qquad 23^{\circ} 29^{\prime} 38,4^{\prime \prime S} 48^{\circ} 28^{\prime} 29^{\prime \prime W}\end{array}$ & 615 & 2 & 03.IV.2001 \\
\hline 2 & SP & $\begin{array}{l}\text { Município de Paranapanema, Sítio Santa Luzia, riacho sem nome } \\
\qquad 23^{\circ} 24^{\prime} 34,5^{\prime \prime S} 48^{\circ} 53^{\prime} 55,2^{\prime \prime} \mathrm{W}\end{array}$ & 659 & 1 & 22.IV.2001 \\
\hline 3 & SP & $\begin{array}{l}\text { Município de Cerqueira César, Córrego Virado } \\
23^{\circ} 05^{\prime} 45.2^{\prime \prime S} 49^{\circ} 12 \text { '36, } 4^{\prime W}\end{array}$ & 486 & 3 & 20.IV.2001 \\
\hline 4 & SP & $\begin{array}{l}\text { Município de Pirajú, Chácara Monte Alegre, riacho sem nome } \\
23^{\circ} 144^{\prime} 46,9^{\prime \prime} \mathrm{S} 49^{\circ} 20^{\prime} 20,4^{\prime \prime} \mathrm{W}\end{array}$ & 599 & 2 & 21.IV.2001 \\
\hline 5 & SP & $\begin{array}{l}\text { Município de São Pedro do Turvo, Ribeirão Claro } \\
22^{\circ} 48^{\prime} 12,4^{\prime \prime} \mathrm{S} 49^{\circ} 47^{\prime} 04,7^{\prime \prime} \mathrm{W}\end{array}$ & 500 & 2 & 18.IV.2001 \\
\hline 6 & SP & $\begin{array}{l}\text { Município de Jacarezinho, Fazenda Sertãozinho, Riacho Água Seca } \\
\qquad 23^{\circ} 10^{\prime} 41,2^{\prime \prime} \mathrm{S} 49^{\circ} 52^{\prime} 52,9^{\prime \prime} \mathrm{W}\end{array}$ & 488 & 2 & 19.IV.2001 \\
\hline 7 & SP & $\begin{array}{l}\text { Município de Salto Grande, Sítio Santo Antonio, Ribeirão Santana } \\
222^{\circ} 49^{\prime} 03,1^{\prime \prime} \text { S } 49^{\circ} 58^{\prime} 24,2^{\prime \prime} \text { W }\end{array}$ & 447 & 3 & 02.IX.2000 \\
\hline 8 & PR & $\begin{array}{l}\text { Município de Andirá, Fazenda das Antas, Córrego das Águas das Antas } \\
\qquad 23^{\circ} 02^{\prime} 56^{\prime \prime} \mathrm{S} 50^{\circ} 11^{\prime} 50,7^{\prime \prime}\end{array}$ & 421 & 3 & 04.IX.2000 \\
\hline 9 & SP & $\begin{array}{l}\text { Município de Cruzália, Córrego Água do Macaco } \\
22^{\circ} 39^{\prime} 46,9^{\prime \prime} \mathrm{S} 50^{\circ} 49^{\prime} 39,5^{\prime \prime} \mathrm{W}\end{array}$ & 352 & 1 & 06.IX.2000 \\
\hline 10 & PR & $\begin{array}{l}\text { Município de Rancho Alegre, Fazenda Fartura, Córrego Água da Laranjinha } \\
23^{\circ} 02^{\prime} 30^{\prime \prime} \mathrm{S} 50^{\circ} 53^{\prime} 26,3^{\prime \prime} \mathrm{W}\end{array}$ & 358 & 1 & 05.IX.2000 \\
\hline 11 & SP & $\begin{array}{l}\text { Município de Iepê, Fazenda Jaguaretê, Córrego Congonha } \\
22^{\circ} 32^{\prime} 46,3^{\prime \prime S} 51^{\circ} 07^{\prime} 04,7^{\prime \prime W}\end{array}$ & 399 & 1 & 07.IX.2000 \\
\hline 12 & PR & $\begin{array}{l}\text { Município de Centenário do Sul, Sítio Nova Vida, Córrego da Boa Esperança } \\
\qquad 22^{\circ} 51^{\prime} 9,4^{\prime \prime} \mathrm{S} 51^{\circ} 35^{\prime} 8,5^{\prime} \mathrm{W}\end{array}$ & 417 & 2 & 03.VIII.2000 \\
\hline 13 & SP & $\begin{array}{l}\text { Município de Narandiba, Fazenda São José, riacho sem nome } \\
22^{\circ} 37^{\prime} 50,5^{\prime \prime} \mathrm{S} 51^{\circ} 27^{\prime} 44,1^{\prime \prime} \mathrm{W}\end{array}$ & 336 & 2 & 02.VIII.2000 \\
\hline 14 & PR & $\begin{array}{l}\text { Município de Paranavaí, Fazenda Rancho de Zinco e Cristo Rei, Córrego Santa Clara } \\
\qquad 22^{\circ} 45^{\prime} 54,2^{\prime} \mathrm{S} 52^{\circ} 25^{\prime} 19,0^{\prime \prime W}\end{array}$ & 287 & 1 & 08.VIII.2000 \\
\hline 15 & SP & $\begin{array}{l}\text { Município de Teodoro Sampaio, Ribeirão da Estação } \\
22^{\circ} 30^{\prime} 29,4^{\prime \prime} \mathrm{S} 52^{\circ} 26^{\prime} 07,5^{\prime \prime} \mathrm{W}\end{array}$ & 296 & 1 & 06.VIII.2000 \\
\hline 16 & PR & $\begin{array}{l}\text { Município de Diamante do Norte, Fazenda Água Mole, Córrego Água Mole } \\
\qquad 22^{\circ} 38^{\prime} 31,7^{\prime \prime S} 52^{\circ} 48^{\prime} 59,0^{\prime \prime} \mathrm{W}\end{array}$ & 289 & 1 & 07.VIII.2000 \\
\hline 17 & SP & $\begin{array}{c}\text { Município de Euclides da Cunha, Rio do Piau } \\
22^{\circ} 33^{\prime} 04,9^{\prime \prime} \mathrm{S} 52^{\circ} 44^{\prime} 36,3^{\prime \prime} \mathrm{W} \\
\end{array}$ & 285 & 1 & 05.VIII.2000 \\
\hline
\end{tabular}


Tabela 2. Fisiografia, dados físico-químicos, transparência horizontal da água, composição granulométrica predominante da amostra de fundo no ponto médio (cf. Cummins, 1962 ) e vegetação do entorno nos 17 trechos de riachos amostrados na bacia do Rio Paranapanema.

\begin{tabular}{|c|c|c|c|c|c|c|c|c|c|c|}
\hline Trechos & $\begin{array}{l}\text { Variação da } \\
\text { largura }(\mathbf{m})\end{array}$ & $\begin{array}{c}\text { Variação da } \\
\text { profundidade (m) }\end{array}$ & 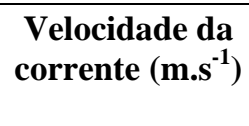 & $\begin{array}{c}\text { Temperaturas } \\
\text { do ar e da } \\
\text { água }\left({ }^{\circ} \mathrm{C} /{ }^{\circ} \mathrm{C}\right)\end{array}$ & pH & $\begin{array}{c}\text { Oxigênio } \\
\text { dissolvido } \\
\left(\mathrm{mg}^{-L^{-1}}\right)\end{array}$ & $\begin{array}{c}\text { Condutividade } \\
\left(\mu \mathrm{S} . \mathrm{cm}^{-1}\right)\end{array}$ & $\begin{array}{l}\text { Transparência } \\
\text { horizontal (m) }\end{array}$ & $\begin{array}{c}\text { Granulometria } \\
\text { dominante do } \\
\text { substrato }\end{array}$ & $\begin{array}{r}\text { Vegetação } \\
\text { do entorno }\end{array}$ \\
\hline 1 & $1,4-3,3$ & $0,06-0,6$ & 0,21 & $24,5 / 20,9$ & 7,80 & $*$ & 142,7 & 0,40 & $\begin{array}{c}\text { grânulos e } \\
\text { areia muito } \\
\text { grossa }\end{array}$ & pastagem \\
\hline 2 & $2,3-3,3$ & $0,1-0,2$ & 0,75 & $20,1 / 19,7$ & 8,48 & * & 479 & 0,50 & $\begin{array}{c}\text { grânulos e } \\
\text { areia grossa }\end{array}$ & pastagem \\
\hline 3 & $1,7-3,5$ & $0,1-0,8$ & 0,12 & $24,5 / 19,3$ & 8,28 & $*$ & 46,9 & 0,60 & $\begin{array}{c}\text { areia grossa e } \\
\text { média }\end{array}$ & pastagem \\
\hline 4 & $0,6-2,3$ & $0,1-0,6$ & 1,0 & $26,6 / 19,5$ & 8,04 & $*$ & 43,3 & 0,40 & $\begin{array}{l}\text { grânulos e } \\
\text { areia muito } \\
\text { grossa }\end{array}$ & pastagem \\
\hline 5 & $1,5-3,0$ & $0,3-1,0$ & 0,18 & $27,8 / 22,1$ & 8 & $*$ & 30,3 & 0,65 & $\begin{array}{c}\text { saibro } \\
\text { e areia fina }\end{array}$ & pastagem \\
\hline 6 & $1,4-4,0$ & $0,02-0,4$ & $\sim 0$ & $23,5 / 20,2$ & 8,07 & $*$ & 199,9 & 1,10 & $\begin{array}{l}\text { areia média e } \\
\text { fina }\end{array}$ & pastagem \\
\hline 7 & $4,3-6,2$ & $0,03-0,25$ & 0,90 & $16,5 / 18,7$ & 7,2 & 9,9 & 67 & 0,20 & $\begin{array}{l}\text { pedras e } \\
\text { cascalho }\end{array}$ & pastagem \\
\hline 8 & $2,3-3,9$ & $0,01-0,16$ & 0,46 & $14,9 / 15,3$ & 7,6 & 10,9 & 111 & 0,20 & $\begin{array}{l}\text { grânulos e } \\
\text { areia muito } \\
\text { grossa }\end{array}$ & mata \\
\hline 9 & $1,10-2,32$ & $0,04-0,38$ & 0,29 & $15,3 / 17,2$ & 7,4 & 9,5 & 151 & 0,25 & $\begin{array}{l}\text { saibro e } \\
\text { cascalho }\end{array}$ & pastagem \\
\hline
\end{tabular}

http://www.biotaneotropica.org.br 


\begin{tabular}{|c|c|c|c|c|c|c|c|c|c|c|}
\hline 10 & $2,00-2,50$ & $0,04-0,24$ & 0,23 & $15,5 / 14,8$ & 7,6 & 9,7 & 118 & 0,40 & $\begin{array}{l}\text { areia média e } \\
\text { fina }\end{array}$ & milharal \\
\hline 11 & $1,51-2,79$ & $0,01-0,40$ & 0,53 & $17,8 / 17,9$ & 7,7 & 9,1 & 24 & 0,39 & $\begin{array}{l}\text { cascalho } \\
\text { arenoso } \\
\text { e cascalho }\end{array}$ & pastagem \\
\hline 12 & $1,51-2,00$ & $0,04-0,20$ & 0,15 & $19,5 / 16,6$ & 7,7 & 8,3 & 65 & 1,26 & $\begin{array}{l}\text { areia média } \\
\text { e fina }\end{array}$ & pastagem \\
\hline 13 & $2,0-4,4$ & $0,05-0,32$ & 0,24 & $23,0 / 17,7$ & 7,6 & 9,4 & 72 & 1,36 & $\begin{array}{l}\text { areia média } \\
\text { e fina }\end{array}$ & pastagem \\
\hline 14 & $1,1-2,1$ & $0,20-0,72$ & 0,42 & $28,0 / 21,4$ & 7,6 & 11,3 & 30 & 0,74 & $\begin{array}{l}\text { areia média } \\
\text { e fina }\end{array}$ & mata \\
\hline 15 & $2,8-4,3$ & $0,13-0,66$ & 0,65 & $17,7 / 18,4$ & 7,9 & 8,9 & 15 & 0,56 & $\begin{array}{c}\text { areia média } \\
\text { e grossa }\end{array}$ & pastagem \\
\hline 16 & $0,7-1,0$ & $0,17-0,4$ & 0,20 & $31,0 / 18,6$ & 8,7 & 10,6 & 17 & 0,40 & $\begin{array}{l}\text { areia média } \\
\text { e fina }\end{array}$ & pastagem \\
\hline 17 & $2,65-4,20$ & $0,20-0,92$ & 0,47 & $24,3 / 17,2$ & 8,1 & 9,6 & 21 & 0,53 & $\begin{array}{l}\text { cascalho e } \\
\text { areia grossa }\end{array}$ & pastagem \\
\hline
\end{tabular}

* Valores não obtidos devido à falha irreparável dos oxímetros no campo. 
Tabela 3. Descrição geral sucinta dos 17 trechos de riachos amostrados na bacia do Rio Paranapanema.

\begin{tabular}{ll}
\hline Trechos & Descrição
\end{tabular}

1 Traçado sinuoso; margens com declividade mediana e barrancos entre 0,2-1,5 $\mathrm{m}$ de altura; com alternância de corredeiras e poços; margens com predominância de "capins" (Poaceae - Brachiaria sp.) e arbustos (Euphorbiaceae - Croton urucurana).

2 Traçado sinuoso; margens com declividade acentuada e barrancos de até 1,5 $\mathrm{m}$ de altura; com alternância de poços e corredeiras; margens com predominância de Heliconiaceae (Heliconia sp.), Campanulaceae (Centropogon sp.) e "samambaias" (Pterydophyta - Thelypteridaceae).

3 Traçado sinuoso; margens com barrancos de até $30 \mathrm{~cm}$ de altura e declividade variável; pequenas praias e corredeiras presentes; margens dominadas por "capins-navalha" (Cyperaceae - Rhynchospora aurea), "cruzes-de-malta" (Onagraceae - Ludwigia sp.) e pequenas campanuláceas.

4 Traçado pouco sinuoso; margens com barrancos de até $2 \mathrm{~m}$ de altura; com alternância de poços e corredeiras; leito com algumas rochas maiores em trechos mais correntosos. Margens com predominância de "begônias" (Begoniaceae), "lírios-do-brejo" (Zingiberiaceae - Hedychium sp.) e "trapoerabas" (Commelinaceae - Commelina sp.).

5 Traçado pouco sinuoso; margens com 30-40 cm de altura (declividade de $45^{\circ}$ ); parcialmente encaixado; com corredeiras e pequenos poços intercalados; leito com galhadas e troncos submersos; margens alagadas, com predominância de "trapoerabas" (Commelinaceae - Tradescantia sp.) e "lírios-do-brejo" (Zingiberiaceae - Hedychium sp.).

6 Traçado bem pouco sinuoso; margens com barrancos quase verticais de até $90 \mathrm{~cm}$ de altura; pequenas praias presentes; com alternância de poços e pequenas corredeiras rasas; leito com algumas rochas maiores; margens com predominância de Melastomataceae, Haloragaceae (Myriophyllum aquaticum) e "capins" (Poaceae - Croix lacryma-jobi).

7 Traçado pouco sinuoso; margens de baixa declividade, com pequenas praias; leito predominantemente rochoso; margens com predominância de "samambaias" (Pterydophyta - Thelypteridaceae) e "trapoerabas" (Commelinaceae - Commelina sp.).

8 Traçado pouco sinuoso; margens com barrancos de até $90^{\circ}$ de declividade; trecho superior lêntico, com galhadas e folhiço; ponto médio com queda d'água de $3 \mathrm{~m}$, seguida de corredeiras; leito rochoso no trecho médio; margens com predominância de Piperaceae (Piper cf. tuberculatum) e Commelinaceae (Tradescantia sp. e Tradescantia zebrina).

9 Trecho sinuoso; margens variando entre pequenas praias e barrancos íngremes; com corredeiras e pequenos poços no terço médio; margens com predominância de "samambaias" (Pterydophyta - Thelypteridaceae), "trapoerabas" (Commelinaceae - Commelina sp.) e "capins" (Poaceae). 
10 Trecho sinuoso; margens variando entre pequenas praias e barrancos íngremes; com alternância de poços e corredeiras; leito rochoso na sua maior parte; margens repletas de "samambaias" (Pterydophyta - Thelypteridaceae) e "pimenteiras" (Piperaceae - Piper cf. tuberculatum).

11 Traçado sinuoso; margens com barrancos com até $90^{\circ}$ de inclinação; predominância de corredeiras, pequenos poços marginais, com galhadas semisubmersas; margens com predominância de Commelinaceae (Commelina sp.) e Zingiberiaceae (Hedychium sp.).

12 Traçado sinuoso; margens com barrancos de 1,5-4,0 m de altura (declividade $70^{\circ}-90^{\circ}$ ); com predominância de áreas de corredeiras rasa; leito rochoso, com acúmulo de areia nos poços; margens com predominância de Piperaceae (Piper cf. tuberculatum) e Poaceae (Leersia sp.).

13 Traçado pouco sinuoso; margens com declividade suave $\left(30^{\circ}-40^{\circ}\right)$, com alguns barrancos verticais de até $2,5 \mathrm{~m}$ de altura; com alternância de pequenas corredeiras e poços rasos; margens com predominância de Piperaceae (Piper cf. tuberculatum).

14 Traçado sinuoso; margens com declividade suave; sem poços e corredeiras definidos; leito com pouco folhiço e algumas galhadas maiores; margens alagadas, com predominância de "trapoerabas" (Commelinaceae - Tradescantia sp.) e "capins" (Poaceae).

15 Traçado medianamente sinuoso; margens com declividade acentuada $\left(60^{\circ}-70^{\circ}\right)$, com até $13 \mathrm{~m}$ de altura; com pequenas quedas d'água e corredeiras e poços relativamente profundos; leito com afloramentos de arenito tabular friável; margens com predominância de Piperaceae (Piper cf. tuberculatum).

16 Traçado pouco sinuoso; margens quase planas, canal encaixado em canaleta relativamente profunda; leito com pouco folhiço; margens com predominância de "capins" (Cyperaceae - Fimbristylis sp.) e samambaias (Pterydophyta - Polypodiacea).

17 Traçado sinuoso; margens com declividade suave e canal principal encaixado em ravina com margens quase verticais; sem definição clara de poços e corredeiras; margens com predominância de Piperaceae (Piper cf. tuberculatum) e Heliconiaceae (Heliconia sp.) 

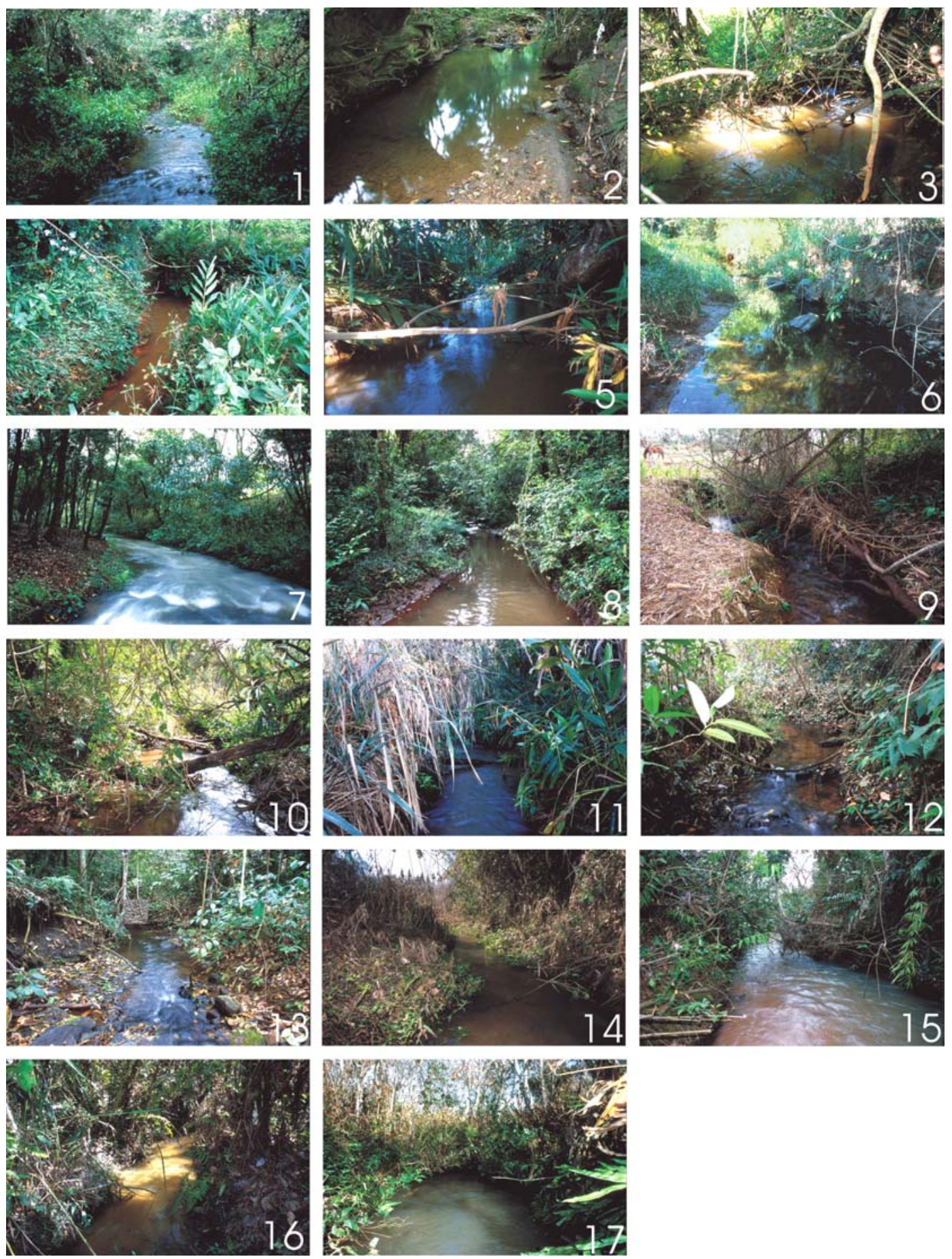

Figura 5. Vistas dos pontos médios dos 17 trechos de riachos amostrados na bacia do Rio Paranapanema. As respectivas coordenadas geográficas e numerações de campo são apresentadas entre parênteses: 1) Córrego Poço dos Patos (23²9'38,4"S 48²8'29"W - APA 042);

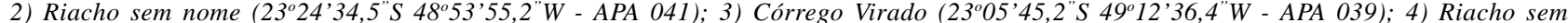

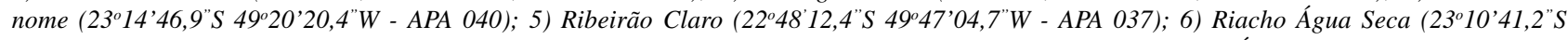

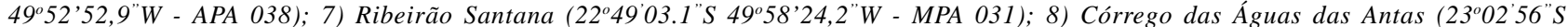

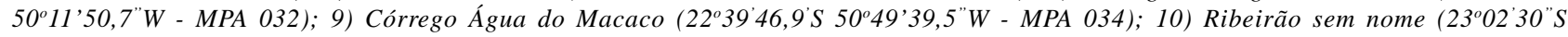

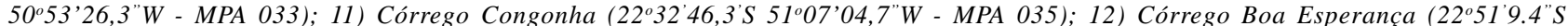

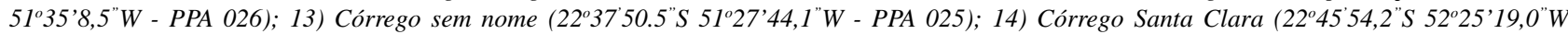

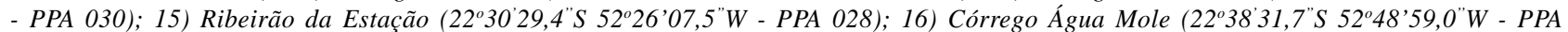

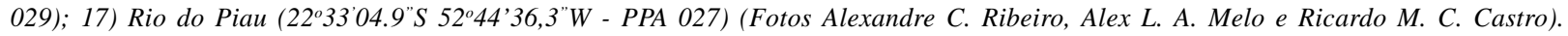


Foram coletados 3.683 exemplares, pertencentes a seis ordens, 16 famílias, 37 gêneros e 52 espécies (Tabela 4), perfazendo uma biomassa total de $16,8 \mathrm{~kg}$. Das espécies coletadas, aproximadamente $36 \%$ pertencem a ordem Siluriformes, $36 \%$ a Characiformes, $11 \%$ a Gymnotiformes, $10 \%$ a Perciformes, $4 \%$ a Cyprinodontiformes e $2 \%$ a Synbranchiformes. Apenas 17 (aproximadamente 0,5\% do total) dos exemplares coletados (Figuras 6 a 9), têm comprimento padrão superior a $150 \mathrm{~mm}$ (Tabelas 5.a a 5.c e
Figuras. 6 a 9). As espécies mais abundantes foram Astyanax altiparanae (15,2\%) e Astyanax sp. 1 (12,3\%); as com maior biomassa foram A. altiparanae (28\%) e Geophagus brasiliensis (13\%). A composição da ictiocenose, em termos de abundância e biomassa por família, indica a predominância expressiva de Characidae, seguida por Loricariidae, Pimelodidae e Cichlidae (Figura 10). Com relação ao número de espécies, as ordens Siluriformes e Characiformes tiveram maior representatividade, com aproximadamente $36 \%$ do total de espécies coletadas cada uma delas.

Tabela 4. Lista das espécies de peixes coletadas nos 17 trechos riachos estudados na bacia do Rio Paranapanema, SP e PR.

\author{
Ordem Characiformes \\ Família Erythrinidae \\ Família Characidae \\ Hoplias malabaricus (Bloch, 1794) \\ Subfamília Tetragonopterinae \\ Astyanax altiparanae Garutti \& Britski, 2000 \\ Astyanax fasciatus (Cuvier, 1819) \\ Astyanax scabripinnis Eigenmann, 1914 \\ Astyanax sp. 1 \\ Astyanax sp. 2 \\ Bryconamericus stramineus (Eigenmann, 1908) \\ Bryconamericus sp. \\ Moenkhausia sanctaefilomenae (Steindachner, 1907) \\ Oligosarcus paranensis Menezes \& Géry, 1983 \\ Oligosarcus pintoi Campos, 1945 \\ Piabina argentea Reinhardt, 1866 \\ Subfamília Cheirodontinae \\ Serrapinnus notomelas (Eigenmann, 1915) \\ Família Crenuchidae \\ Serrapinnus sp. \\ Família Curimatidae \\ Characidium gomesi Travassos, 1956 \\ Characidium zebra Eigenmann, 1909 \\ Família Anostomidae \\ Cyphocharax modestus (Fernández-Yèpez, 1948) \\ Família Parodontidae \\ Leporinus paranensis Garavello \& Britski, 1987 \\ Apareiodon piracicabae Eigenmann, 1907 \\ Ordem Siluriformes \\ Família Pimelodidae \\ Subfamília Heptapterinae \\ Cetopsorhamdia iheringi Schubart \& Gomes, 1959 \\ Imparfinis mirini Haseman, 1911 \\ Imparfinis schubarti (Gomes, 1956) \\ Pimelodella sp. \\ Rhamdia quelen (Quoy \& Gaimard, 1824) \\ Phenacorhamdia tenebrosa (Schubart, 1964) \\ Subfamília Pimelodinae \\ Pimelodus maculatus LaCepède, 1803
}

http://www.biotaneotropica.org.br 
Família Auchenipteridae

Tatia neivai (Ihering, 1930)

Família Trichomycteridae

Eremophilus sp.

Trichomycterus sp.

Família Callichthyidae

Subfamília Callichthyinae

Callichthys callichthys (Linnaeus, 1758)

Subfamília Corydoradinae Corydoras aeneus (Gill, 1858)

Família Loricariidae

Subfamília Neoplecostominae

Neoplecostomus paranensis Langeani, 1990

Subfamília Hypoptopomatinae

Hisonotus sp. 1

Hisonotus sp. 2

Subfamília Loricariinae

Rineloricaria pentamaculata Langeani \& Araujo, 1994

Subfamília Hypostominae

Hypostomus ancistroides (Ihering, 1911)

Hypostomus nigromaculatus (Schubart, 1964)

Hypostomus regani (Ihering, 1905)

Ordem Gymnotiformes

Família Sternopygidae

Família Gymnotidae

Eigenmannia virescens (Valenciennes, 1847)

Sternopygus macrurus (Bloch \& Schneider, 1801)

Gymnotus cf. carapo Linnaeus, 1758

Gymnotus cf. inaequilabiatus (Valenciennes, 1842)

Gymnotus cf. sylvius Albert \& Fernandes-Matioli, 1999

Gymnotus sp.

Ordem Cyprinodontiformes

Família Poeciliidae

Phalloceros caudimaculatus (Hensel, 1868)

Poecilia reticulata Peters, $1859 *$

Ordem Synbranchiformes

Família Synbranchidae

Synbranchus marmoratus Bloch, 1795

Ordem Perciformes

Família Cichlidae

Subfamília Pseudocrenilabrinae

Oreochromis niloticus (Linnaeus, 1758) *

Tilapia rendalli (Boulenger, 1897) *

Subfamília Cichlasomatinae

Cichlasoma paranaense Kullander, 1983

Subfamília Cichlinae

Crenicichla britskii Kullander, 1982

Subfamília Geophaginae

Geophagus brasiliensis (Quoy \& Gaimard, 1824)

* espécies introduzidas

http://www.biotaneotropica.org.br 

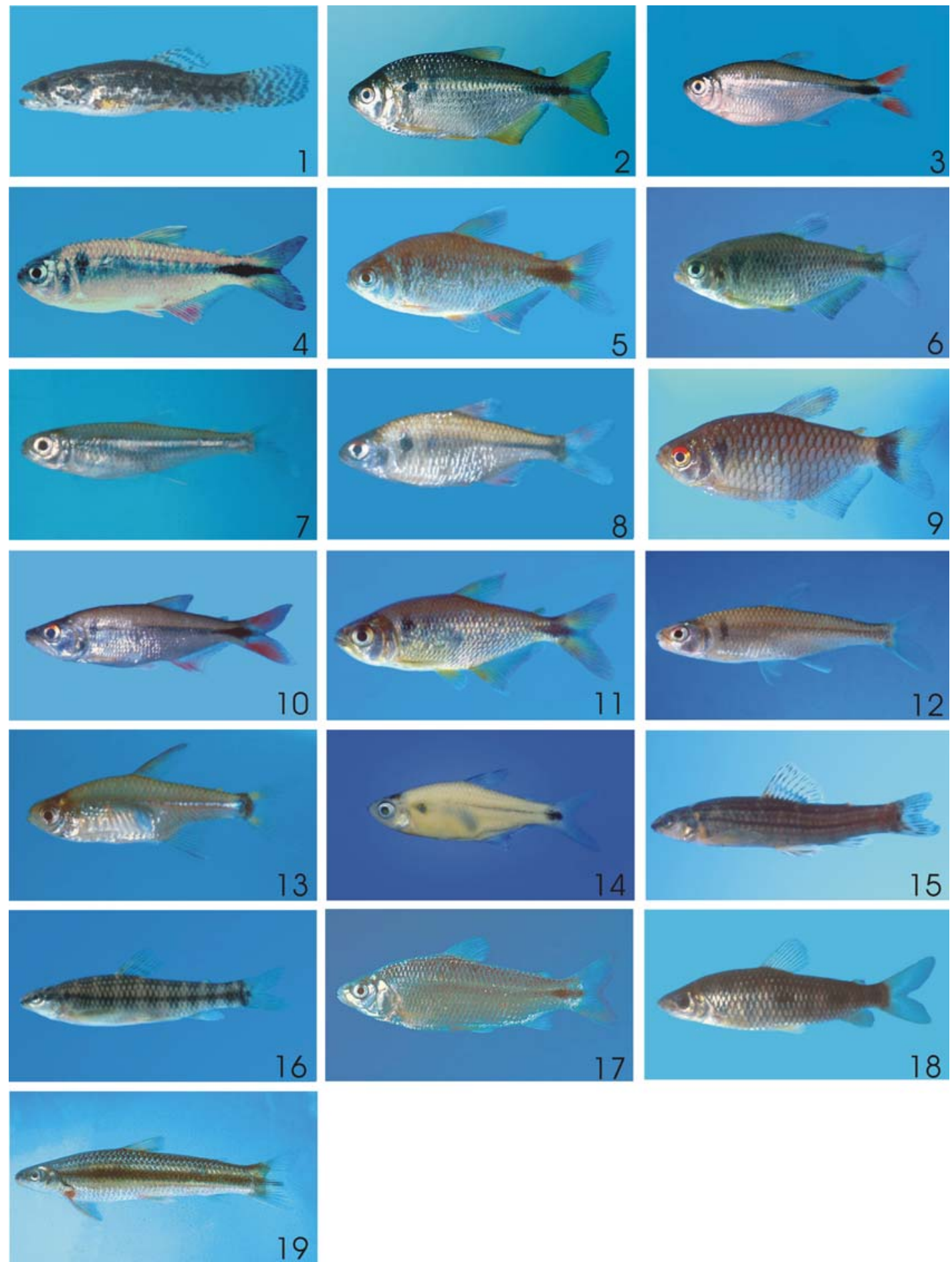

Figura 6. Exemplares representativos das espécies de peixes da ordem Characiformes coletadas na bacia do Rio Paranapanema. Os respectivos números de registro na coleção ictiológica do LIRP e comprimentos padrões são apresentados após os nomes das espécies: 1) Hoplias malabaricus, LIRP 1694, 53,3 mm; 2) Astyanax altiparanae, LIRP 2878, 83,3 mm; 3) Astyanax fasciatus, LIRP 2755, 65,7 mm; 4) Astyanax scabripinnis, LIRP 2680, 61,3 mm; 5) Astyanax sp.1, LIRP 2748, 48,2 mm; 6) Astyanax sp.2, LIRP 2734, 94,6 mm; 7) Bryconamericus stramineus, LIRP 2793, 41,0 mm; 8) Bryconamericus sp., LIRP 2784, 47,6 mm; 9) Moenkhausia sanctaefilomenae, LIRP 2390, 56,8 mm; 10) Oligosarcus paranaensis, LIRP 2395, 70,3 mm; 11) Oligosarcus pintoi, LIRP 1695, 52,0 mm; 12) Piabina argentea, LIRP 2418, 60,6 mm; 13) Serrapinnus notomelas, LIRP 2505, 24,5 mm; 14) Serrapinnus sp., LIRP 2491, 25,0 mm; 15) Characidium gomesi, LIRP 2507, 56,1 mm; 16) Characidium zebra, LIRP 2518, 52,4 mm; 17) Cyphocharax modestus, LIRP 2347, 104,1 mm; 18) Leporinus paranensis, LIRP 2254, 101,5 mm; 19) Apareiodon piracicabae, LIRP 2553, 90,8 mm (Fotos Alexandre C. Ribeiro, Alex L. A. Melo e Ricardo M. C. Castro). 

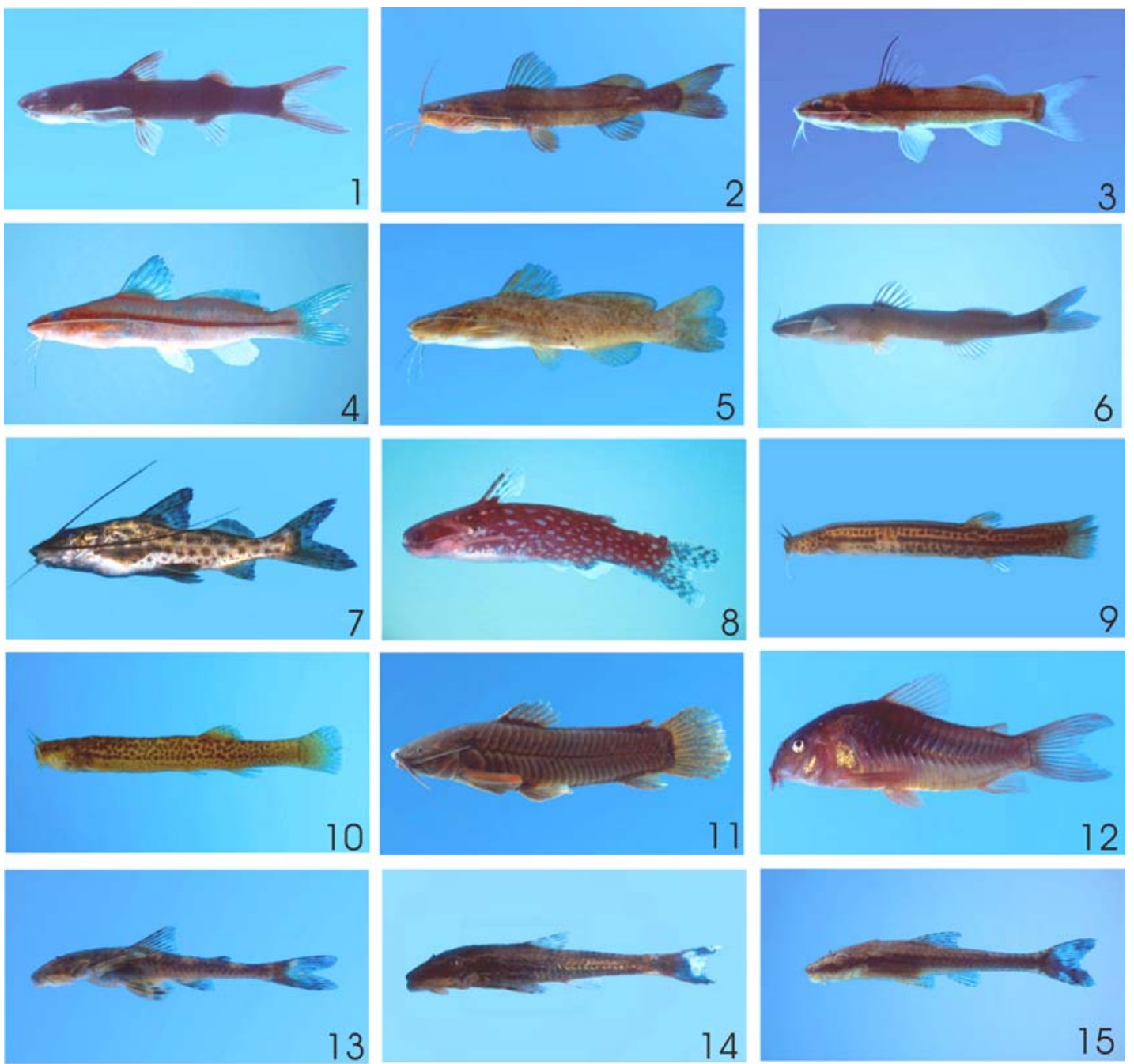

13

14
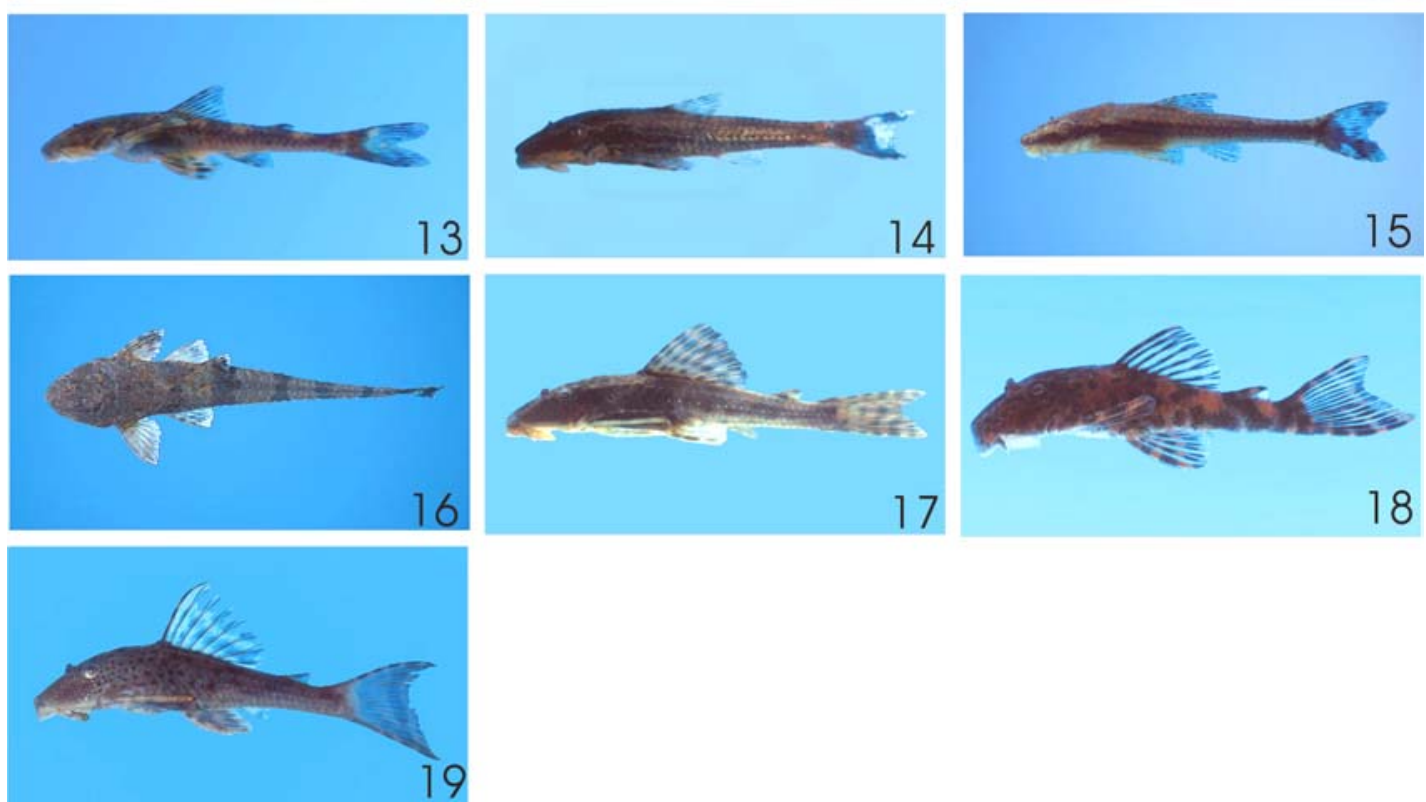

Figura 7. Exemplares representativos das espécies de peixes da ordem Siluriformes coletadas na bacia do Rio Paranapanema. Os seus respectivos números de registro na coleção ictiológica do LIRP e comprimentos padrões são apresentados após os nomes das espécies: 1) Cetopsorhamdia iheringi, LIRP 2809, 57,3 mm; 2) Imparfinis schubarti, LIRP 2943, $76.8 \mathrm{~mm}$; 3) Imparfinis mirini, LIRP 2948, 76,3 mm; 4) Pimelodella $s p$., LIRP 2924, 74,9 mm; 5) Rhamdia quelen, LIRP 1698, 90,0 mm; 6) Phenacorhamdia tenebrosa, LIRP 2873, 58,2 mm; 7) Pimelodus maculatus, LIRP 2392, 89,9 mm; 8) Tatia neivai, LIRP 2413, 45,9 mm; 9). Eremophilus sp., LIRP 2801, 43,6 mm; 10) Trichomycterus sp., LIRP 2800, 48,6 mm; 11) Callichthys callichthys, LIRP 2541, 83,1 mm; 12) Corydoras aeneus, LIRP 1700, $39,4 \mathrm{~mm}$; 13) Neoplecostomus paranensis, LIRP 2778, $96,9 \mathrm{~mm}$; 14) Hisonotus sp.1, LIRP 2267, $24,2 \mathrm{~mm}$; 15) Hisonotus sp.2, LIRP 2262, 33,4 mm; 16) Rineloricaria pentamaculata, LIRP 2777, 95,6 mm; 17) Hypostomus ancistroides, LIRP 1701, 83,3 mm; 18) Hypostomus nigromaculatus, LIRP 1702, 36,8 mm; 19) Hypostomus regani, LIRP 2660, 73,0 mm (Fotos Alexandre C. Ribeiro, Alex L. A. Melo e Ricardo M. C. Castro). 

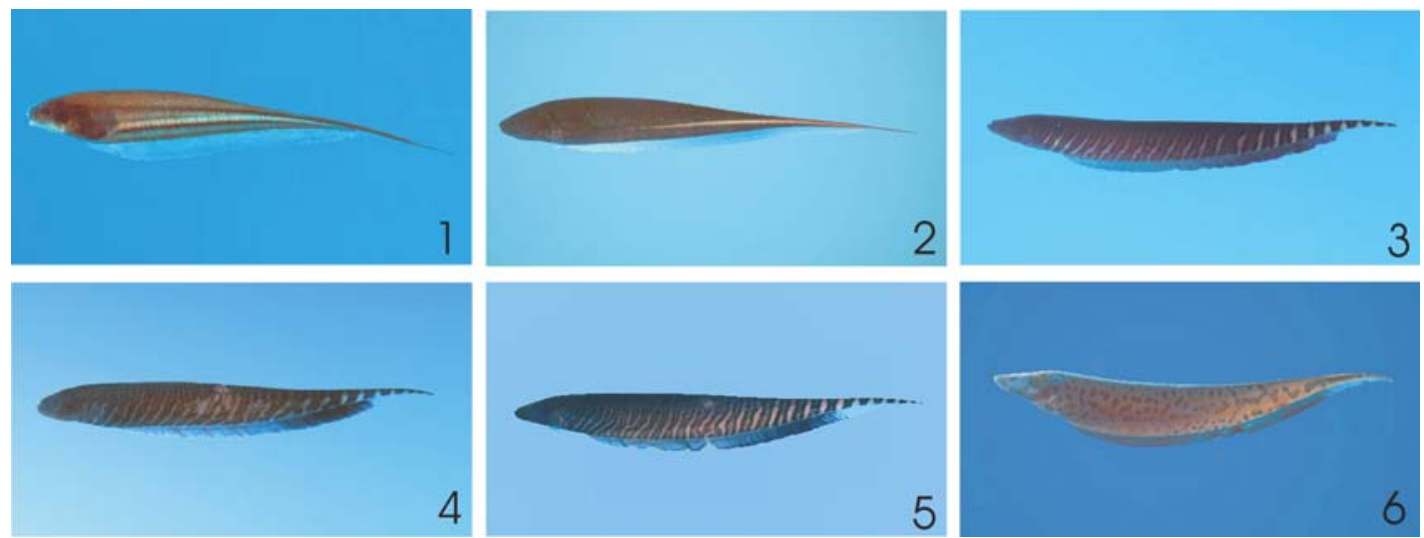

Figura 8. Exemplares representativos das espécies de peixes da ordem Gymnotiformes coletadas na bacia do Rio Paranapanema. Os respectivos números de registro na coleção ictiológica do LIRP e comprimentos totais são apresentados após os nomes das espécies: 1) Eigenmannia virescens, LIRP 2822, 131,0 mm; 2) Sternopygus macrurus, LIRP 2815, 180,6 mm; 3) Gymnotus cf. carapo, LIRP 2859, 196,4 mm; 4) Gymnotus $c f$. inaequilabiatus, LIRP 2861, 84,1 mm; 5) Gymnotus $c f$. sylvius, LIRP 2841, 134,1 mm; 6) Gymnotus sp., LIRP 2866 , 194,8 mm (Fotos Alexandre C. Ribeiro, Alex L. A. Melo e Ricardo M. C. Castro).
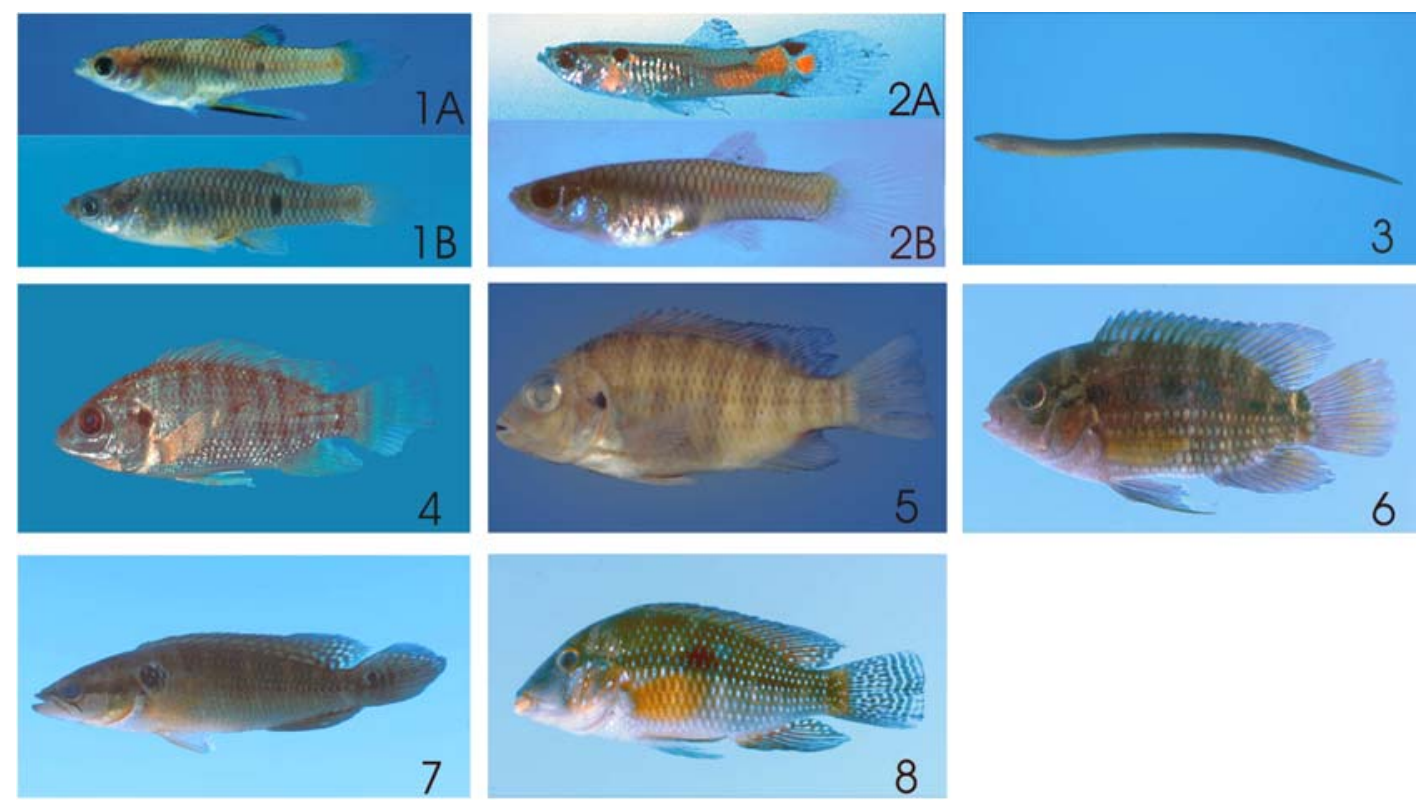

Figura 9. Exemplares representativos das espécies de peixes das ordens Cyprinodontiformes, Synbranchiformes e Perciformes coletadas na bacia do Rio Paranapanema. Os respectivos números de registro na coleção ictiológica do LIRP e comprimentos padrões (comprimento total, figura 9.3) são apresentados após os nomes das espécies: 1) Phalloceros caudimaculatus, A (macho), LIRP 1704, 19,9 mm, B (fêmea), LIRP 1704, 25,9 mm; 2) Poecilia reticulata, A (macho), LIRP 2641, 19,3 mm, B (fêmea), LIRP 2635, 22,9 mm; 3) Synbranchus marmoratus, LIRP 2575, 173,0 mm; 4) Oreochromis niloticus, LIRP 2594, 57,6 mm; 5) Tilapia rendalli, LIRP 2592, 59,0 mm; 6) Cichlasoma paranaense, LIRP 2608, 71,1 mm; 7) Crenicichla britskii, LIRP 2576, 68,0 mm; 8) Geophagus brasiliensis, LIRP 2655, 67,1 mm (Fotos Alexandre C. Ribeiro, Alex L. A. Melo e Ricardo M. C. Castro). 
Tabela 5a. Número total de indivíduos coletados (N), amplitude do comprimento padrão (CP) em mm e biomassa total (BM) em gramas dos peixes coletados nos trechos de riachos de números 1 a 6 da bacia do Rio Paranapanema.

\begin{tabular}{|c|c|c|c|c|c|c|c|c|c|c|c|c|c|c|c|c|c|c|}
\hline \multirow{2}{*}{$\begin{array}{l}\text { Trechos } \\
\text { Espécies }\end{array}$} & \multicolumn{3}{|c|}{1} & \multicolumn{3}{|c|}{2} & \multicolumn{3}{|c|}{3} & \multicolumn{3}{|c|}{4} & \multicolumn{3}{|c|}{5} & \multicolumn{3}{|c|}{6} \\
\hline & $\mathbf{N}$ & $\mathbf{C P}$ & BM & $\mathbf{N}$ & $\mathbf{C P}$ & $\overline{\text { BM }}$ & $\mathbf{N}$ & $\mathbf{C P}$ & BM & $\mathbf{N}$ & $\mathbf{C P}$ & $\overline{\text { BM }}$ & $\mathbf{N}$ & $\mathbf{C P}$ & BM & $\mathbf{N}$ & $\mathbf{C P}$ & $\overline{B M}$ \\
\hline Astyanax altiparanae & 40 & $36,7-75,8$ & 254,5 & - & - & - & - & - & - & 10 & $43,3-78,4$ & 83 & 3 & $51,1-72,2$ & 24 & 12 & $56,3-90,6$ & 205 \\
\hline Astyanax fasciatus & 23 & $21,7-71,6$ & 75,5 & 28 & $33,9-61,3$ & 107 & 44 & $17,8-90,3$ & 116 & - & - & - & - & - & - & - & - & - \\
\hline Astyanax scabripinnis & - & - & - & - & - & - & - & - & - & - & - & - & 3 & $17,2-61,3$ & 13,5 & 132 & $23,5-85,6$ & 348,5 \\
\hline Astyanax sp. 1 & - & - & - & 68 & $24,0-61,2$ & 174 & 5 & $23,7-58,5$ & 10,5 & 18 & $22,8-49,4$ & 30,5 & - & - & - & 322 & $26,1-64,7$ & 816,5 \\
\hline Bryconamericus sp. & - & - & - & 185 & $12,3-49,9$ & 184,5 & - & - & - & - & - & - & - & - & - & 103 & $38,7-42,9$ & 264,5 \\
\hline Callichthys callichthys & - & - & - & 19 & $43,4-78,0$ & 119 & - & - & - & - & - & - & - & - & - & - & - & - \\
\hline Cetopsorhamdia iheringi & - & - & - & - & - & - & 3 & $25,7-41,6$ & 1,5 & - & - & - & - & - & - & - & - & - \\
\hline Cyphocharax modestus & 5 & $40,4-106,7$ & 105 & - & - & - & - & - & - & - & - & - & - & - & - & - & - & - \\
\hline Eigenmannia virescens & - & - & - & - & - & - & 15 & $46,3-158,1$ & 79 & - & - & - & - & - & - & - & - & - \\
\hline Eremophilus sp. & - & - & - & - & - & - & 1 & 43,6 & 0,5 & - & - & - & - & - & - & - & - & - \\
\hline Geophagus brasiliensis & 17 & $26,4-99,2$ & 229 & 10 & $26,7-91,7$ & 167,5 & 6 & $21,2-122,2$ & 93 & - & - & - & 2 & $58,9-68,1$ & 19 & 254 & $15,0-107,5$ & 1685,5 \\
\hline Gymnotus cf. carapo & - & - & - & - & - & - & - & - & - & 1 & 84,1 & 2 & - & - & - & - & - & - \\
\hline Gymnotus cf. inaequilabiatus & - & - & - & - & - & - & - & - & - & 1 & 132 & 16 & - & - & - & - & - & - \\
\hline Gymnotus sp. & 1 & 194,8 & 27,5 & - & - & - & - & - & - & - & - & - & - & - & - & - & - & - \\
\hline Gymnotus cf. sylvius & 4 & $131,7-178,3$ & 61 & - & - & - & - & - & - & - & - & - & 2 & $46,9-149,8$ & 11,5 & - & - & - \\
\hline Hisonotus sp. 1 & - & - & - & - & - & - & 124 & $18,7-37,4$ & 108,5 & 22 & $12,8-33,6$ & 8,5 & - & - & - & - & - & - \\
\hline Hoplias malabaricus & 3 & $78,6-123,5$ & 73 & - & - & - & 4 & $43,4-80,4$ & 106 & - & - & - & - & - & - & 1 & 104 & 25 \\
\hline Hypostomus ancistroides & 7 & $34,8-56,8$ & 18 & 5 & $27,9-46,4$ & 6 & 31 & $21,4-76,2$ & 71 & 1 & 68,5 & 7,5 & 5 & $20,1-48,7$ & 9 & 3 & $32,1-49,0$ & 6 \\
\hline Imparfinis mirini & 3 & $31,5-71,6$ & 8 & - & - & - & 5 & $39,3-47,7$ & 9 & 35 & $25,5-58,6$ & 55,5 & 1 & 36,9 & 1 & 2 & $67,0-76,6$ & 5 \\
\hline Oligosarcus paranensis & - & - & - & 2 & $75,8-79,2$ & 17,5 & 2 & $38,0-42,4$ & 2,5 & - & - & - & - & - & - & 13 & $24,1-83,4$ & 60 \\
\hline Oreochromis niloticus & 7 & $22,0-69,2$ & 26,5 & - & - & - & - & - & - & - & - & - & - & - & - & - & - & - \\
\hline Phalloceros caudimaculatus & - & - & - & 6 & $13,5-32,2$ & 2 & 12 & $13,5-24,4$ & 3 & - & - & - & - & - & - & 91 & $14,0-38,1$ & 29 \\
\hline Phenacorhamdia tenebrosa & - & - & - & - & - & - & 1 & 27,9 & 0,5 & - & - & - & - & - & - & - & - & - \\
\hline Piabina argentea & 7 & $27,8-48,9$ & 8 & - & - & - & 15 & $22,0-61,8$ & 45,5 & - & - & - & - & - & - & - & - & - \\
\hline Pimelodella sp. & 1 & 105,6 & 21,5 & - & - & - & 16 & $33,4-81,6$ & 46,5 & - & - & - & - & - & - & - & - & - \\
\hline Pimelodus maculatus & 4 & $89,9-116,5$ & 93,5 & - & - & - & - & - & - & - & - & - & - & - & - & - & - & - \\
\hline Rhamdia quelen & - & - & - & 1 & 124,7 & 32,5 & - & - & - & 4 & $17,5-78,9$ & 10 & - & - & - & - & - & - \\
\hline Rineloricaria pentamaculata & - & - & - & - & - & - & 17 & $25,4-103,7$ & 56,5 & - & - & - & - & - & - & - & - & - \\
\hline Serrapinnus notomelas & 6 & $14,4-26,9$ & 2 & - & - & - & - & - & - & - & - & - & - & - & - & - & - & - \\
\hline Serrapinnus sp. & 2 & $22,9-23,9$ & 1 & - & - & - & - & - & - & - & - & - & - & - & - & - & - & - \\
\hline Synbranchus marmoratus & 1 & 173,1 & 7,5 & - & - & - & - & - & - & - & - & - & - & - & - & - & - & - \\
\hline Tilapia rendalli & - & - & - & - & - & - & 1 & 59 & 9 & - & - & - & - & - & - & - & - & - \\
\hline Trichomycterus sp. & - & - & - & 33 & $16,7-85,3$ & 93,5 & - & - & - & 1 & 48,6 & 1,5 & - & - & - & - & - & - \\
\hline Totais & 131 & & 1011,5 & 357 & & 903,5 & 302 & & 758,5 & 93 & & 214,5 & 16 & & 78 & 933 & & 3445 \\
\hline
\end{tabular}


Tabela 5b. Número total de indivíduos coletados (N), amplitude do comprimento padrão (CP) em mm, e biomassa total (BM) em gramas dos peixes coletados nos trechos de riachos 7 a 11 da bacia do Rio Paranapanema.

\begin{tabular}{|c|c|c|c|c|c|c|c|c|c|c|c|c|c|c|c|}
\hline \multirow{2}{*}{$\begin{array}{ll} & \text { Trechos } \\
\text { Espécies } & \end{array}$} & \multicolumn{3}{|c|}{7} & \multicolumn{3}{|c|}{8} & \multicolumn{3}{|c|}{9} & \multicolumn{3}{|c|}{10} & \multicolumn{3}{|c|}{11} \\
\hline & $\mathbf{N}$ & $\mathbf{C P}$ & $\overline{\mathbf{B M}}$ & $\mathbf{N}$ & $\mathbf{C P}$ & $\mathbf{B M}$ & $\mathbf{N}$ & $\mathbf{C P}$ & BM & $\mathbf{N}$ & $\mathbf{C P}$ & BM & $\mathbf{N}$ & $\mathbf{C P}$ & BM \\
\hline Apareiodon piracicabae & 5 & $53,3-109,4$ & 86,5 & - & - & - & - & - & - & - & - & - & - & - & - \\
\hline Astyanax altiparanae & 12 & $33,7-91,3$ & 148 & 30 & $40,7-85,1$ & 283 & 27 & $42,5-94,3$ & 468,5 & 249 & $33,2-79,4$ & 1174 & - & - & - \\
\hline Astyanax fasciatus & - & - & - & - & - & - & 8 & $30,2-76,7$ & 23 & - & - & - & - & - & - \\
\hline Astyanax scabripinnis & 13 & $69,0-92,3$ & 191,5 & 8 & $23,7-63,1$ & 26 & - & - & - & - & - & - & - & - & - \\
\hline Astyanax sp. 1 & 35 & $18,1-76,9$ & 278 & 1 & 63,5 & 8,5 & 1 & 72,6 & 4,5 & 1 & 57,1 & 5 & - & - & - \\
\hline Bryconamericus sp. & - & - & - & 1 & 41,4 & 2 & - & - & - & - & - & - & - & - & - \\
\hline Bryconamericus stramineus & - & - & - & - & - & - & - & - & - & - & - & - & 29 & $26,0-49,7$ & 29,5 \\
\hline Cetopsorhamdia iheringi & - & - & - & 45 & $28,1-73,0$ & 83 & - & - & - & - & - & - & - & - & - \\
\hline Characidium gomesi & - & - & - & - & - & - & - & - & - & - & - & - & 5 & $38,3-47,8$ & 9 \\
\hline Characidium zebra & - & - & - & 2 & $38,7-42,9$ & 1 & - & - & - & 3 & $43,6-62,3$ & 8,5 & - & - & - \\
\hline Cichlasoma paranaense & - & - & - & - & - & - & 2 & $69,3-73,9$ & 43 & 1 & 71,1 & 23 & - & - & - \\
\hline Corydoras aeneus & 20 & $28,3-44,1$ & 149,5 & - & - & - & 99 & $25,6-45,6$ & 212,5 & 27 & $29,3-41,5$ & 57,5 & - & - & - \\
\hline Crenicichla britskii & 3 & $67,7-78,4$ & 30 & - & - & - & 5 & $64,6-113,6$ & 101 & - & - & - & - & - & - \\
\hline Gymnotus cf. inaequilabiatus & - & - & - & - & - & - & 4 & $140,0-155,0$ & 70,5 & - & - & - & 5 & $78,2-130,9$ & 38 \\
\hline Gymnotus cf. sylvius & - & - & - & - & - & - & 2 & $138,7-155,0$ & 47 & - & - & - & - & - & - \\
\hline Hoplias malabaricus & - & - & - & - & - & - & 2 & $84,8-140,0$ & 78,5 & 1 & 153,6 & 88 & - & - & - \\
\hline Hypostomus ancistroides & - & - & - & 1 & 105,1 & 29 & 15 & $44,3-64,2$ & 71 & 29 & $27,2-87,5$ & 115 & 1 & 87,4 & 19,5 \\
\hline Hypostomus regani & 19 & $36,4-111,6$ & 320 & 12 & $42,2-88,6$ & 120 & - & - & - & - & - & - & - & - & - \\
\hline Imparfinis mirini & 1 & 76,3 & 7,5 & 31 & $29,2-49,6$ & 32,5 & 53 & $23,2-67,8$ & 81 & 20 & $35,2-63,3$ & 52 & - & - & - \\
\hline Imparfinis schubarti & - & - & - & 1 & 39,5 & 1 & 2 & $38,8-56,1$ & 5 & - & - & - & - & - & - \\
\hline Neoplecostomus paranensis & - & - & - & - & - & - & - & - & - & - & - & - & 3 & $32,7-69,1$ & 7,5 \\
\hline Phenacorhamdia tenebrosa & - & - & - & - & - & - & 3 & $45,0-70,9$ & 6,5 & - & - & - & - & - & - \\
\hline Piabina argentea & - & - & - & 1 & 44,8 & 2,5 & - & - & - & - & - & - & 14 & $46,3-56,8$ & 22,5 \\
\hline Pimelodella sp. & - & - & - & 157 & $33,2-80,0$ & 334 & 8 & $39,9-48,4$ & 9,5 & - & - & - & - & - & - \\
\hline Poecilia reticulata & 7 & $14,2-23,9$ & 1 & - & - & - & - & - & - & 1 & 19,3 & 0,5 & - & - & - \\
\hline Rhamdia quelen & 1 & 143,2 & 51,5 & 11 & $54,0-161,2$ & 190 & 15 & $34,4-130,0$ & 187,5 & 21 & $69,4-137,8$ & 417,5 & 3 & $96,9-114,5$ & 88 \\
\hline Serrapinnus notomelas & 9 & $16,0-30,9$ & 4,5 & - & - & - & - & - & - & 1 & 24,4 & 0,5 & - & - & - \\
\hline Synbranchus marmoratus & 2 & $47,7-198,6$ & 9,5 & - & - & - & - & - & - & - & - & - & - & - & - \\
\hline Totais & 127 & & 1277,5 & 301 & & 1112,5 & 246 & & 1409 & 354 & & 1941,5 & 60 & & 214 \\
\hline
\end{tabular}


Tabela 5c. Número total de indivíduos coletados (N), amplitude do comprimento padrão (CP) em mm e biomassa total (BM) em gramas dos peixes coletados nos trechos de riachos 12 a 17 da bacia do Rio Paranapanema.

\begin{tabular}{|c|c|c|c|c|c|c|c|c|c|c|c|c|c|c|c|c|c|c|}
\hline Trechos & & 12 & & & 13 & & & 14 & & & 15 & & & 16 & & & 17 & \\
\hline Espécies & $\mathbf{N}$ & $\mathbf{C P}$ & $\mathbf{B M}$ & $\mathbf{N}$ & $\mathbf{C P}$ & $\mathbf{B M}$ & $\mathbf{N}$ & $\mathbf{C P}$ & BM & $\mathbf{N}$ & $\mathbf{C P}$ & BM & $\mathbf{N}$ & $\mathbf{C P}$ & $\mathbf{B M}$ & $\mathbf{N}$ & $\mathbf{C P}$ & $\mathbf{B M}$ \\
\hline Astyanax altiparanae & - & - & - & 160 & $36,2-101,9$ & 1736 & 11 & $55,3-92,5$ & 151 & - & - & - & - & - & - & 6 & $64,5-94,6$ & 110 \\
\hline Astyanax fasciatus & - & - & - & - & - & - & 12 & $49,1-87,7$ & 142,5 & - & - & - & - & - & - & 1 & 75,4 & 13,5 \\
\hline Astyanax sp. 2 & - & - & - & - & - & - & - & - & - & - & - & - & 77 & $28,1-55,3$ & 199 & - & - & - \\
\hline Bryconamericus stramineus & - & - & - & - & - & - & 8 & $38,1-52,5$ & 12 & 29 & $32,7-56,4$ & 54 & - & - & - & 21 & $18,6-59,2$ & 54,5 \\
\hline Callichthys callichthys & - & - & - & - & - & - & - & - & - & - & - & - & 2 & $70,9-83,1$ & 32,5 & - & - & - \\
\hline Cetopsorhamdia iheringi & - & - & - & - & - & - & 3 & $44,2-57,6$ & 48,5 & - & - & - & - & - & - & 5 & $44,0-77,5$ & 22 \\
\hline Characidium gomesi & - & - & - & - & - & - & 4 & $39,8-56,1$ & 10 & - & - & - & - & - & - & - & - & - \\
\hline Characidium zebra & - & - & - & - & - & - & 5 & $49,5-57,7$ & 15,5 & 1 & 53,1 & 4 & - & - & - & - & - & - \\
\hline Corydoras aeneus & 4 & $30,9-39,5$ & 10 & 1 & 39,4 & 3 & 7 & $26,0-37,5$ & 17 & - & - & - & 3 & $29,1-30,8$ & 6 & - & - & - \\
\hline Crenicichla britskii & - & - & - & - & - & - & 3 & $44,9-60,8$ & 13 & 3 & $45,8-65,5$ & 15 & 1 & 89,6 & 30,5 & - & - & - \\
\hline Eigenmannia virescens & - & - & - & - & - & - & - & - & - & 4 & $103,4-131,0$ & 28 & - & - & - & - & - & - \\
\hline Gymnotus cf. carapo & - & - & - & - & - & - & 3 & $111,5-153,0$ & 34,5 & - & - & - & - & - & - & - & - & - \\
\hline Gymnotus cf. inaequilabiatus & - & - & - & - & - & - & - & - & - & - & - & - & 1 & 147,6 & 10 & 1 & 155 & 13 \\
\hline Gymnotus cf. sylvius & 3 & $133,0-190,0$ & 37,5 & - & - & - & 1 & 196,4 & 22,5 & - & - & - & 2 & $56,5-139,0$ & 22 & - & - & - \\
\hline Hisonotus sp. 1 & - & - & - & - & - & - & 87 & $20,9-36,9$ & 47 & 17 & $24,0-37,4$ & 13 & - & - & - & 39 & $30,1-36,0$ & 31 \\
\hline Hisonotus sp. 2 & - & - & - & - & - & - & 1 & 24,5 & 0,5 & - & - & - & - & - & - & - & - & - \\
\hline Hoplias malabaricus & - & - & - & 1 & 57,3 & 5 & - & - & - & - & - & - & - & - & - & - & - & - \\
\hline Hypostomus ancistroides & 11 & $19,7-52,1$ & 21 & 13 & $28,1-83,3$ & 46 & 8 & $34,3-74,6$ & 28,5 & 25 & $27,0-88,4$ & 90 & - & - & - & 15 & $30,2-74,1$ & 58 \\
\hline Hypostomus nigromaculatus & - & - & - & - & - & - & - & - & - & 15 & $19,5-71,0$ & 85,5 & - & - & - & 1 & 36,8 & 2 \\
\hline Hypostomus regani & - & - & - & - & - & - & - & - & - & 5 & $51,1-93,0$ & 55 & - & - & - & - & - & - \\
\hline Imparfinis mirini & - & - & - & - & - & - & 9 & $31,4-60,9$ & 15 & - & - & - & - & - & - & - & - & - \\
\hline Leporinus paranensis & - & - & - & - & - & - & 1 & 101,5 & 23 & - & - & - & - & - & - & - & - & - \\
\hline Moenkhausia sanctaefilomenae & - & - & - & - & - & - & 9 & $52,1-63,4$ & 56,5 & - & - & - & - & - & - & - & - & - \\
\hline Oligosarcus pintoi & - & - & - & - & - & - & 1 & 52 & 4 & - & - & - & - & - & - & - & - & - \\
\hline Phalloceros caudimaculatus & - & - & - & 36 & $12,1-27,0$ & 15 & 1 & 26,1 & 0,5 & - & - & - & 2 & $18,0-21,6$ & 1 & - & - & - \\
\hline Phenacorhamdia tenebrosa & - & - & - & - & - & - & 1 & 68,1 & 2,5 & 1 & $53,3-58,0$ & 2,5 & - & - & - & 3 & $25,6-70,5$ & 6 \\
\hline Piabina argentea & - & - & - & - & - & - & 13 & $47,5-78,3$ & 64 & - & - & - & - & - & - & - & - & - \\
\hline Pimelodella sp. & - & - & - & - & - & - & 1 & 92,5 & 11,5 & - & - & - & - & - & - & - & - & - \\
\hline Rhamdia quelen & - & - & - & - & - & - & 8 & $65,2-120,5$ & 140,5 & 6 & $60,1-88,4$ & 55,5 & 24 & $60,9-111,3$ & 337 & 1 & 155 & 66 \\
\hline Sternopygus macrurus & - & - & - & - & - & - & 2 & $207,0-228,6$ & 64 & - & - & - & - & - & - & 3 & $180,6-310,5$ & 114,5 \\
\hline Synbranchus marmoratus & 1 & 173 & 5,5 & - & - & - & - & - & - & - & - & - & - & - & - & - & - & - \\
\hline Tatia neivai & - & - & - & - & - & - & - & - & - & - & - & - & - & - & - & 1 & 45,9 & 3 \\
\hline Trichomycterus sp. & 18 & $26,1-82,4$ & 54,5 & - & - & - & - & - & - & - & - & - & - & - & - & - & - & - \\
\hline Totais & 37 & & 128,5 & 211 & & 1805 & 200 & & 928 & 106 & & 402,5 & 112 & & 638 & 97 & & 493,5 \\
\hline
\end{tabular}




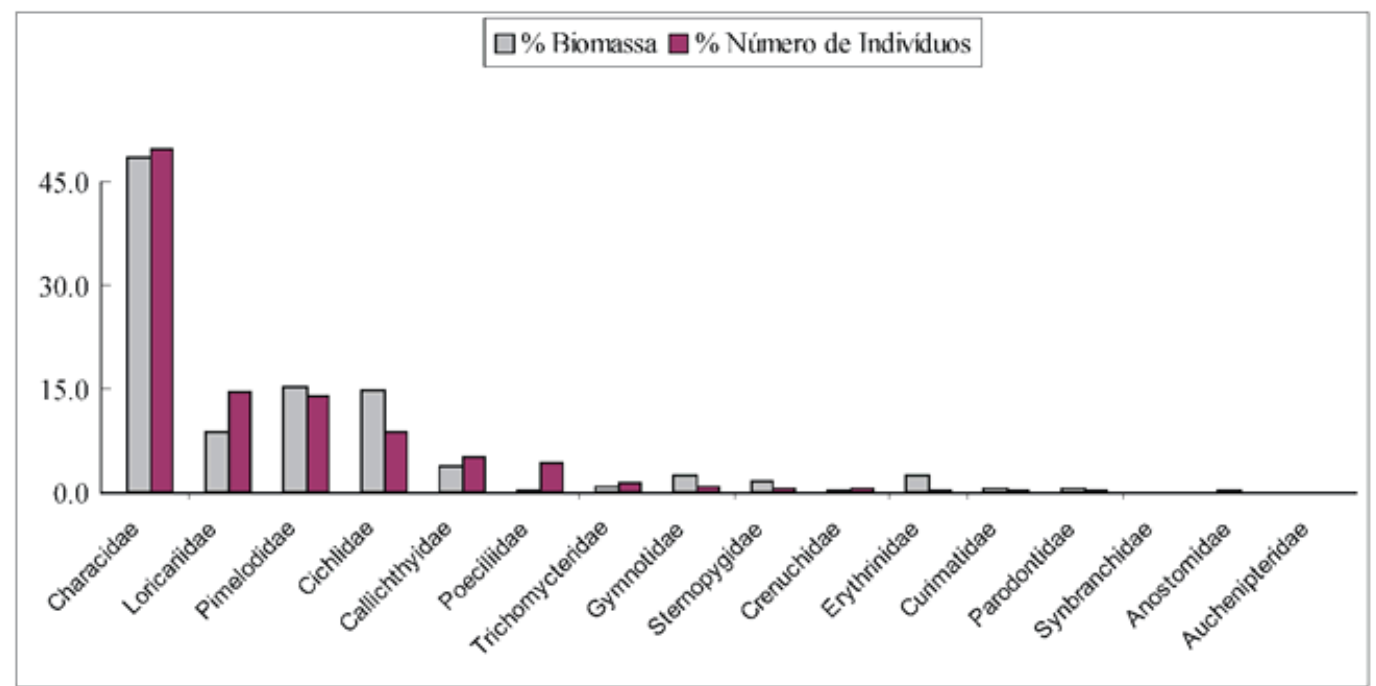

Figura 10. Composição percentual por família, em termos de número de indivíduos e biomassa, da totalidade dos peixes coletados nos 17 trechos de riacho amostrados na bacia do Rio Paranapanema, SP e PR.

Dentre os trechos amostrados, o trecho 14 (com 24 espécies), e o trecho 13 (com cinco espécies), apresentaram a maior e menor riqueza, respectivamente, coincidindo com os valores obtidos do índice de diversidade específica de Shannon-Wienner $\left(\mathrm{H}^{\prime}=0,99\right.$ e 0,32 , respectivamente). A riqueza média em espécies por trecho de riacho foi 11 . O trecho 13 apresentou a maior diversidade específica de Simpson $(\mathrm{D}=0,61)$, enquanto que os trechos um, cinco e sete apresentaram os menores valores deste índice ( $\mathrm{D}=$ $0,15)$. O trecho cinco apresentou maior equitabilidade $(\mathrm{E}=$ $0,94)$, enquanto que o trecho 13 foi o menos uniforme $(\mathrm{E}=$ 0,46) (Tabela 6).

A estimativa de riqueza, por extrapolação, para o conjunto total de riachos amostrados na bacia do Rio Paranapanema, revelou um valor de 69 espécies (erro padrão igual a quatro). Analisando a curva de acumulação do número de espécies em função do número de indivíduos coletados (Figura 11), nota-se que, apesar de existir uma tendência à estabilização, ainda seria provavelmente necessário um esforço amostral adicional moderado para

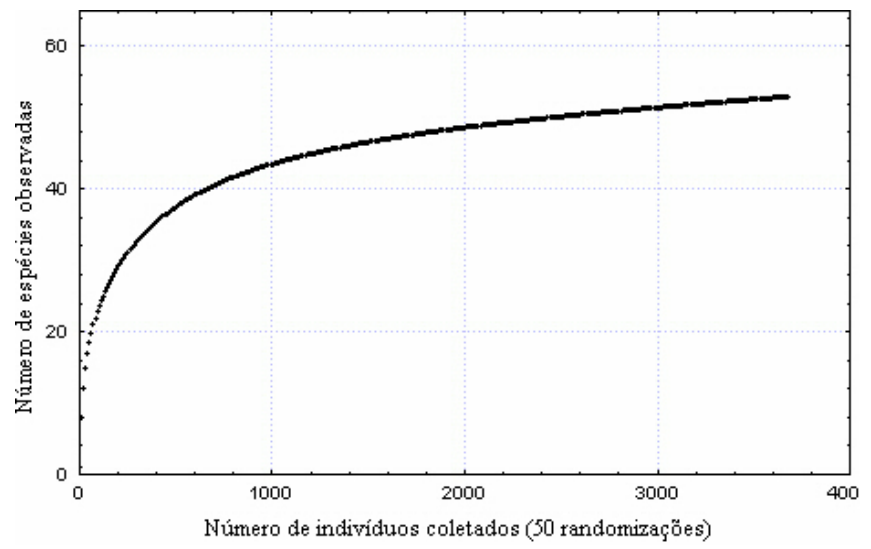

Figura 11. Curva de acumulação do número de espécies observadas em função do número de indivíduos coletados. atingir a assíntota da curva.

Das 52 espécies coletadas, oito (aproximadamente 15\% do total) são seguramente novas: Astyanax sp. 1, Astyanax sp. 2, Bryconamericus sp., Serrapinnus sp., Gymnotus sp., Eremophilus sp., Trichomycterus sp. e Hisonotus sp. 2 (as duas primeiras e as duas últimas estão em fase adiantada de descrição por membros de nossa equipe). Cinco outras espécies (aproximadamente 10\% do total) possuem "status" taxonômico ainda indefinido: Pimelodella sp., Hisonotus sp. 1, Gymnotus cf. carapo, Gymnotus cf. inaequilabiatus e Gymnotus cf. sylvius. Finalmente, é necessário apontar que Poecilia reticulata, Oreochromis niloticus e Tilapia rendalli são espécies introduzidas (aproximadamente $6 \%$ do total), a primeira originária do norte da América do Sul e América Central (Wischnath, 1993), e as duas últimas do continente Africano (Agostinho \& Júlio Jr., 1999; Berra, 2001). Uma chave de identificação para todas as espécies de peixes coletadas é fornecida no item de número seis deste trabalho.

\section{Discussão}

O fato das espécies das ordens Siluriformes e Characiformes, quando somadas, representarem $72 \%$ da diversidade de espécies dos trechos de riachos estudados está de acordo com valores similiares encontrados em riachos não estuarinos da região Neotropical (Lowe-McConnell, 1987, 1999; Castro, 1999) e também registrada em riachos da Amazônia (Soares, 1979; Sabino \& Zuanon, 1998), na bacia do Rio São Francisco (Casatti \& Castro, 1998), no leste do Brasil (Costa, 1984; Bizerril, 1994; Mazzoni \& Lobón-Cervia, 2000), em riachos da Mata Atlântica (Sabino \& Castro, 1990; Aranha et al., 1998), no Chaco Oriental da Argentina (Jacobo \& Veron, 1995) e no Alto Rio Paraná (Garutti, 1988; Uieda, 1984; Penczak et al., 1994; Castro \& Casatti, 1997; Pavanelli \& Caramaschi, 1997).

http://www.biotaneotropica.org.br 
A presença de apenas $0,5 \%$ de indivíduos com mais de $15 \mathrm{~cm}$ de comprimento padrão demonstra, inequivocamente, a absoluta dominância de peixes de pequeno porte na ictiofauna dos riachos amostrados, reforçando a hipótese de Castro (1999) de que a predominância de peixes de pequeno porte é o único padrão geral de valor diagnóstico registrado até o momento para a ictiofauna de riachos sul-americanos. Ainda segundo Castro (1999), o pequeno porte, entre outros aspectos, permite aos peixes de riacho a ocupação de micro-hábitats bastante específicos em um ambiente com dimensões físicas reduzidas, resultando no fato que as espécies tendem a passar seus ciclos de vida completos em áreas geograficamente restritas. Tal fato, dado o devido tempo, poderia propiciar taxas relativamente elevadas de especiação alopátrica. De fato, das 52 espécies coletadas, oito (15\% do total) são seguramente novas e cinco ( $10 \%$ do total) possuem "status" taxonômico ainda indefinido, mas com razoável probabilidade de se revelarem novas quando os grupos aos quais pertencem forem revistos. Deste modo, aproximadamente $25 \%$ das espécies coletadas são pouco ou nada conhecidas cientificamente, valor notavelmente elevado para uma bacia hidrográfica tão intensamente utilizada pelo ser humano para geração de energia em seu canal principal e atividades agropecuárias em sua bacia de drenagem, especialmente se levarmos em conta que a região sudeste do país, com especial destaque para o Estado de São Paulo, abriga aproximadamente $60 \%$ da produção científica nacional (Pesquisa FAPESP, 2001:18). Assim, esse elevado percentual de espécies pouco ou nada conhecidas cientificamente reforça a recomendação de Castro \& Menezes (1998) no sentido de priorizar a exploração científica de ambientes de riachos e cabeceiras no Estado de São Paulo.

Considerando os 17 trechos de riachos amostrados na bacia do Rio Paranapanema, a riqueza de espécies variou de 5 a 24 (média de 11 espécies). Já a riqueza de espécies dos 65 trechos de riachos amostrados em boa parte da porção paulista do Alto Rio Paraná durante o Projeto Temático variou de 3 a 25, com valor médio de aproximadamente 13 espécies. Uieda (1984) e Castro \& Casatti (1997), estudando trechos de riachos do Alto Rio Paraná com aproximadamente 100 a 240 m de extensão, encontraram 18 e 19 espécies respectivamente. O fato dos trechos 13 e 14 apresentarem a menor (5) e a maior (24) riqueza em espécies, com valores congruentes para Shannon-Wienner $\left(\mathrm{H}^{\prime}=0,32\right.$ e 0,99 , respectivamente), provavelmente reflete as condições ambientais gerais onde estão inseridos. O trecho 13 , com menor riqueza e diversidade, cruza áreas de vegetação nativa degradadas pela extração de madeira e, principalmente, lavouras de soja, milho e mandioca. Já o trecho 14 encontra-se muito próximo à sua embocadura no Rio Caiuá, de porte significativamente maior, o que provavelmente explica a ocorrência de
Leporinus paranensis, espécie aparentemente típica da calha de rios médios ou pequenos (Flávio C.T. Lima, observação pessoal), assim como provavelmente boa parte de sua elevada riqueza em espécies, uma vez que a adição de espécies a medida que se aproxima da desembocadura de um curso de água - causada provavelmente pelo aumento no nível da água, propiciando a expansão de micro-hábitats, da disponibilidade de alimento, de sítios de desova e de áreas de abrigo de predadores - é fato já constatado em vários estudos realizados em riachos brasileiros (ver p. ex. Lowe-McConnell, 1975, 1999; Garutti, 1988; Barreto \& Uieda, 1998; Uieda \& Barreto, 1999; Uieda \& Uieda, 2001). Em adição, o trecho 14 corre quase completamente incluído em um grande fragmento ( $900 \mathrm{ha}$ ) extremamente bem conservado de Floresta Estacional Semidecidual, que é a reserva legal da Fazenda Rancho de Zinco e Cristo Rei.

Matthews (1998:33), ao discutir os números e espécies encontrados em diferentes comunidades de peixes, cita que amostragens em 222 trechos de riachos de porte pequeno a médio dos E.U.A. apontaram 14,7 como o número médio de espécies e que, apesar de sistemas de lagos e riachos tropicais conterem claramente as mais ricas comunidades de peixes conhecidas, em muitas localidades o número de espécies parece ser em média muito similar aquele encontrado em regiões temperadas do planeta. Aparentemente, a variação na riqueza local em espécies de peixes é influenciada pela posição longitudinal do ponto de coleta no curso de água (expresso pela ordem do trecho coletado), pela diversidade ictiofaunística regional e também pelo tamanho físico do ambiente amostrado. Obviamente, o número de espécies em cada local de coleta é também influenciado pelos grandes padrões biogeográficos de diversidade ictofaunística sub-continentais e continentais. Finalmente, o mesmo autor, levando em conta dados de 1.657 locais de coleta em ambientes lóticos e lênticos, no mundo todo, aponta um número modal variando de sete a oito espécies por local (ver Matthews, 1998:35-39), valor bastante próximo do valor médio de 11 espécies por trecho por nós registrado.

Considerando os 17 trechos amostrados na bacia do Rio Paranapanema, as espécies mais abundantes, em termos de números de indivíduos, foram A. altiparanae e Astyanax sp.1, e aquelas com a maior biomassa foram A. altiparanae e G. brasiliensis. Uieda (1984), Garutti (1988), Penczak et al. (1994), Pavanelli \& Caramaschi (1997) e Castro \& Casatti (1997) também verificaram em seus estudos em riachos na bacia do Alto Rio Paraná que A. bimaculatus (=A. altiparanae) está entre as espécies mais abundantes nos locais de estudo; em adição, Castro \& Casatti (1997) citam A. bimaculatus (=A. altiparanae), com $20,7 \%$ da biomassa total coletada no riacho estudado, como uma das três maiores biomassas específicas obtidas (juntamente com A. fasciatus, com $34,8 \%$, e Rhamdia quelen, com 32,2\%).

Analisando a estrutura trófica e espacial da 
ictiocenose estudada, as dez espécies dominantes nos riachos dividem-se em quatro guildas, refletindo provavelmente a macroorganização característica de nichos ecológicos alimentares nos riachos do sistema do Alto Rio Paraná como um todo, indicando que os trechos de riachos escolhidos, apesar de impactados em graus variados, não foram ainda deleteriamente simplificados.

Os onívoros nectônicos são representados por $A$. altiparanae, Astyanax sp. 1, A. scabripinnis e Bryconamericus sp. (Figuras 6.2, 6.5, 6.4 e 6.8, respectivamente), que correspondem a $40 \%$ do total de indivíduos coletados. Nesta guilda, os principais itens alimentares autóctones são larvas aquáticas de insetos, principalmente Chironomidae, e dentre os itens alóctones destacam-se as formigas (Castro \& Casatti, 1997; Casatti \& Castro, 1998). A espécie dominante, A. altiparanae, forma cardumes de 20 a 50 indivíduos que nadam à meia-água coletando partículas arrastadas pela corrente. Durante a noite, os indivíduos permanecem estacionários nos poços mais profundos dos riachos, mas ocasionalmente podem capturar insetos que caem na água, vindos da vegetação ripária (Casatti, 2002).

Os invertívoros bentônicos incluem Pimelodella sp., Corydoras aeneus e Imparfinis mirini (Figuras 7.4, 7.12 e 7.3, respectivamente), correspondendo a $13,6 \%$ do total de indivíduos coletados. Nesta guilda, a principal tática alimentar empregada na captura do alimento é a especulação do substrato (Sazima, 1986) e os principais itens são autóctones, com predominância de larvas aquáticas de insetos e bivalves (Aranha et al., 1993; Soares-Porto, 1994; Castro \& Casatti, 1997; Amaral et al., 1998).

Dentre os perifitívoros (cf. Uieda et al., 1997), destacam-se Hisonotus sp. 1 e Hypostomus ancistroides (Figuras 7.14 e 7.17, respectivamente), correspondendo a $12,4 \%$ do total de indivíduos coletados. De modo geral, as espécies da subfamília Hypoptopomatinae, aqui representadas por Hisonotus spp., forrageiam em meio à vegetação marginal submersa, enquanto que $H$. ancistroides, um Hypostominae, é mais freqüentemente encontrada junto ao fundo dos riachos (Casatti et al., 2001). $\mathrm{O}$ alimento ingerido consiste de algas e protozoários associados à matéria orgânica, juntamente com sedimento, que compõem a matriz perifítica encontrada sobre substratos submersos (Uieda et al., 1997).

Finalmente, os onívoros bentônicos estão representados por G. brasiliensis (Figura 9.8), que corresponde a 7,8\% do total de indivíduos coletados. Nesta guilda, a tática alimentar empregada é a coleta de substrato e separação de presa ("diggers of localized excavations", cf. Sazima, 1986). Neste processo o peixe, após abocanhar o sedimento, expele as partículas de areia e argila pela boca e aberturas operculares, retendo e ingerindo os itens alimentares (Sabino \& Castro, 1990). O alimento ingerido geralmente compreende larvas aquáticas de insetos, algas e detritos. Esteves \& Aranha (1999) sintetizam os hábitos alimentares e itens predominantes na dieta de peixes de riachos brasileiros e concluem que a categoria alimentar onívoro é predominante, tal como encontrado por nós para a ictiocenose dos peixes de riacho do Rio Paranapanema.

Embora a curva de acumulação do número de espécies em função do número de indivíduos coletados (Figura 11) mostre que a assíntota ainda não foi atingida, em uma coleta experimental realizada em junho de 2000 no córrego Sete de Setembro, Parque Estadual Morro do Diabo, SP, onde foi utilizada a mesma metodologia empregada em nosso Projeto Temático, L. Casatti e H. F. Santos (dados não publicados) verificaram que $53 \%$ da biomassa total obtida foi coletada na primeira passagem de pesca elétrica e que a partir da segunda passagem de pesca elétrica nenhuma espécie inédita foi adicionada à amostra. Não obstante, certas espécies, geralmente com hábitos crípticos durante o dia, tais como boa parte dos Gymnotiformes (8.1 a 8.6) e Tatia neivai (Figura 7.8), são eficiente ou exclusivamente coletadas com auxílio de peneiras. Já as espécies nectônicas, como os lambaris em geral, talvez em função de condutividades relativamente baixas na área de estudo, muitas vezes são capazes de fugir da área de ação da pesca elétrica antes de serem atordoados e capturados. Nestes casos, o arrasto manual é de grande valor como apetrecho auxiliar à pesca elétrica. Assim, acreditamos que a metodologia por nós empregada foi eficiente na obtenção de um retrato instantâneo da estrutura e composição das ictiofaunas amostradas.

Tabela 6. Valores dos índices de diversidade específica de Shannon-Wienner $\left(H^{\prime}\right)$ e de Simpson $(D)$, e Equitatividade (E) para os 17 trechos de riachos amostrados na bacia do Rio Paranapanema, SP e PR.

\begin{tabular}{rccc}
\hline Trechos & Shannon $\left(\mathrm{H}^{\prime}\right)$ & Simpson $(\mathrm{D})$ & Equitatividade $(\mathrm{E})$ \\
\hline $\mathbf{1}$ & $\mathbf{0 , 9 7}$ & $\mathbf{0 , 1 5}$ & $\mathbf{0 , 8 0}$ \\
$\mathbf{2}$ & $\mathbf{0 , 6 5}$ & $\mathbf{0 , 3 2}$ & $\mathbf{0 , 6 5}$ \\
$\mathbf{3}$ & $\mathbf{0 , 8 8}$ & $\mathbf{0 , 2 1}$ & $\mathbf{0 , 7 2}$ \\
4 & $\mathbf{0 , 6 9}$ & $\mathbf{0 , 2 4}$ & $\mathbf{0 , 7 3}$ \\
$\mathbf{5}$ & $\mathbf{0 , 7 3}$ & $\mathbf{0 , 1 5}$ & $\mathbf{0 , 9 4}$ \\
$\mathbf{6}$ & $\mathbf{0 , 7 1}$ & $\mathbf{0 , 2 3}$ & $\mathbf{0 , 7 1}$ \\
$\mathbf{7}$ & $\mathbf{0 , 9 1}$ & $\mathbf{0 , 1 5}$ & $\mathbf{0 , 8 4}$ \\
$\mathbf{8}$ & $\mathbf{0 , 6 8}$ & $\mathbf{0 , 3 2}$ & $\mathbf{0 , 6 1}$ \\
$\mathbf{9}$ & $\mathbf{0 , 8 2}$ & $\mathbf{0 , 2 3}$ & $\mathbf{0 , 6 9}$ \\
10 & $\mathbf{0 , 4 8}$ & $\mathbf{0 , 5 1}$ & $\mathbf{0 , 4 6}$ \\
11 & $\mathbf{0 , 6 4}$ & $\mathbf{0 , 3 0}$ & $\mathbf{0 , 7 6}$ \\
12 & $\mathbf{0 , 5 4}$ & $\mathbf{0 , 3 3}$ & $\mathbf{0 , 7 8}$ \\
13 & $\mathbf{0 , 3 2}$ & $\mathbf{0 , 6 1}$ & $\mathbf{0 , 4 6}$ \\
14 & $\mathbf{0 , 9 9}$ & $\mathbf{0 , 2 1}$ & $\mathbf{0 , 7 1}$ \\
15 & $\mathbf{0 , 8 2}$ & $\mathbf{0 , 1 8}$ & $\mathbf{0 , 8 2}$ \\
16 & $\mathbf{0 , 4 3}$ & $\mathbf{0 , 5 2}$ & $\mathbf{0 , 4 7}$ \\
$\mathbf{1 7}$ & $\mathbf{0 , 7 7}$ & $\mathbf{0 , 2 3}$ & $\mathbf{0 , 7 1}$ \\
\hline
\end{tabular}


6. Chave de identificação para as 52 espécies de peixes coletadas nos 17 trechos de riacho amostrados na bacia do Rio Paranapanema, SP e PR

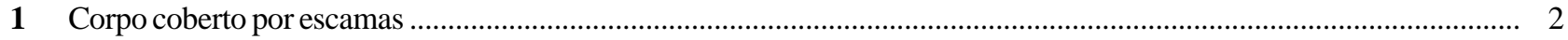

1' Corpo desprovido de escamas ou coberto por placas ósseas .................................................................................... 33

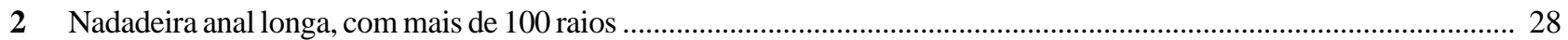

2' Nadadeira anal relativamente curta, com 50 raios ou menos ................................................................................. 3

3 Porte pequeno, inferior a $40 \mathrm{~mm}$ de comprimento; machos com a nadadeira anal transformada em estrutura copuladora

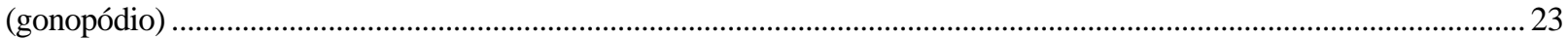

3' Porte na maior parte das vezes superior a $40 \mathrm{~mm}$ de comprimento; machos com nadadeira anal não transformada em estrutura copuladora (gonopódio)....................................................................................................................... 4

4 Boca protráctil, escamas ctenóides e linha lateral divida em dois ramos ...................................................................... 24

4' Boca não protráctil, escamas ciclóides e linha lateral simples, não dividida ............................................................ 5

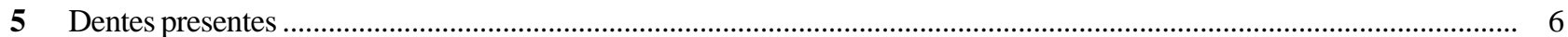

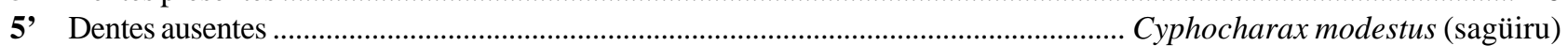

6 Pré-maxilar com uma fileira de dentes .............................................................................................................. 13

6' Pré-maxilar com duas ou mais fileiras de dentes ..................................................................................................... 7

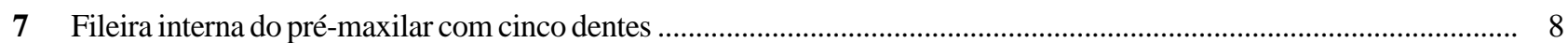

7' Fileira interna do pré-maxilar com quatro dentes ..................................................................................................... 21

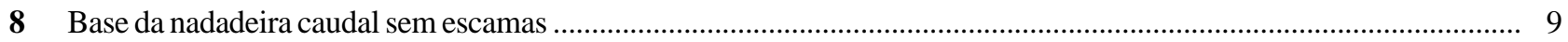

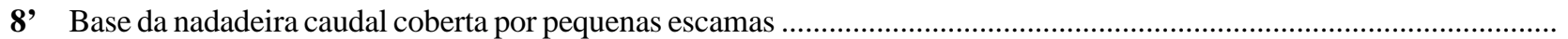

Moenkhausia sanctaefilomenae (olho-de-fogo, lambari)

9 Osso maxilar com um ou mais dentes, mancha umeral com contorno difuso, e verticalmente alongada; nadadeira caudal de coloração hialina-amarelada, alaranjada, rosada ou vermelha em vida.

9' Osso maxilar desprovido de dentes, mancha umeral de contorno bem definido, e horizontalmente ovalada; nadadeira caudal amarela em vida ..Astyanax altiparanae (lambari-do-rabo-amarelo)

10 Limite posterior da base da nadadeira dorsal situado na vertical que passa pela base do primeiro ou segundo raio ramificado da nadadeira anal; padrão de colorido do tronco reticulado; nadadeira caudal hialina-amarelada em vida Astyanax sp. 2 (lambari)

10' Limite posterior da base da nadadeira dorsal situado na vertical que passa pelo ânus ou pela origem da nadadeira anal; tronco sem padrão de colorido reticulado; nadadeira caudal alaranjada, rosada, avermelhada ou vermelha. ... 11

11 Altura do corpo contida de 2,6 a 3,3 vezes no comprimento padrão; mancha umeral verticalmente alongada, difusa e geralmente única; quando muito seguida de área enegrecida informe e difusa posterior 12

11 Altura do corpo contida de 2,2 a 2,9 (mais comumente 2,5) vezes no comprimento padrão; mancha umeral verticalmente alongada, pouco difusa, quase sempre seguida de área escura posterior difusa porém claramente visível; nadadeira caudal rosada ou avermelhada em vida; nadadeira anal com 22 a 26 raios (mais comumente 25 ) ..... Astyanax sp. 1 (lambari)

12 Nadadeira caudal geralmente rosada ou alaranjada em vida; manchas escuras difusas na porção dorso-lateral do corpo; nadadeira anal geralmente com 18 a 23 raios (mais comumente 21) ……........................................................................................ Astyanax scabripinnis (lambari-de-cabeceira)

12' Nadadeira caudal vermelha em vida; sem manchas escuras difusas na porção dorso-lateral do corpo; nadadeira anal geralmente com 24 a 30 raios (mais comumente 25 a 27) Astyanax fasciatus (lambari-do-rabo-vermelho)

13 Pseudotímpano presente. 14

13' Pseudotímpano ausente 
14 Uma mancha negra cobrindo todo o pedúnculo caudal Serrapinnus notomelas (piquira, piaba) 14' Mancha negra apenas envolvendo a porção medial da base da nadadeira caudal ..... Serrapinnus sp. (piquira, piaba)

15 Borda anterior da mandíbula reta e sem dentes Apareiodon piracicabae (canivete)

15' Borda anterior da mandíbula arredondada 16

16 Nadadeira peitoral com três raios anteriores não ramificados ................................................................................. 17

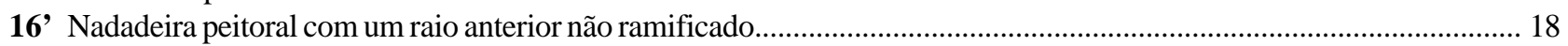

17 Istmo com escamas Characidium zebra (canivete)

17' Istmo sem escamas Characidium gomesi (canivete)

18 Dentes incisiviformes nas maxilas Leporinus paranensis (piau)

18' Dentes cônicos ou tricuspidados nas maxilas . 19

19 Nadadeira adiposa e fontanela frontal ausentes Hoplias malabaricus (traíra)

19' Nadadeira adiposa e fontanela frontal presentes 20

20 Dentes cônicos a fracamente tricuspidados no pré-maxilar; cônicos a tricuspidados no dentário Oligosarcus paranensis (peixe-cachorro, saicanga, tabicum)

20' Dentes tricuspidados no pré-maxilar; tricuspidados a pentacuspidados no dentário

Oligosarcus pintoi (lambari-cachorro)

21 Três fileiras de dentes no pré-maxilar

Piabina argentea (lambari, piaba)

21' Duas fileiras de dentes no pré-maxilar 22

22 Mancha umeral presente Bryconamericus sp. (piaba)

22' Mancha umeral ausente Bryconamericus stramineus (piaba)

23 Fêmeas com coloração dos flancos e dorso castanho claro uniforme, ventre esbranquiçado e nadadeiras hialinas; machos com manchas esféricas negras e áreas de coloração viva variada nos flancos (principalmente metade posterior do corpo e nadadeira dorsal - formas de aquário muitas vezes com a nadadeira caudal expandida e extremamente colorida); gonopódio sem apêndice apical Poecilia reticulata (güaru, lebiste)

23' Machos e fêmeas com padrão de cromatóforos escuros bordejando partes expostas das escamas formando um padrão geral reticulado sobre fundo castanho-claro; uma, ou mais raramente duas, manchas escuras verticalmente ovaladas na metade da altura do corpo, imediatamente abaixo ou um pouco atrás da terminação posterior da base da nadadeira dorsal; gonopódio com apêndice apical Phalloceros caudimaculatus (güaru, barrigudinho)

24 Ramo superior do primeiro arco branquial com lóbulo Geophagus brasiliensis (cará)

24' Ramo superior do primeiro arco branquial sem lóbulo 25

25 Corpo baixo (altura do corpo contida cerca de 3,3 a 3,7 vezes no comprimento padrão); borda posterior do préopérculo serrilhada ou denteada ..... Crenicichla britskii (joaninha)

25' Corpo alto (altura do corpo contida cerca de 2,0 a 2,5 vezes no comprimento padrão); borda posterior do pré-opérculo lisa 26

26 Tronco com mancha ovalada na porção mediana-dorsal; nadadeira dorsal com 13 a 15 espinhos e 10 ou 11 raios flexíveis. Cichlasoma paranaense (cará)

26' Tronco sem mancha ovalada na porção mediana-dorsal; nadadeira dorsal com 15 ou mais espinhos e 13 ou mais raios flexíveis

27 Perfil pré-dorsal convexo; nadadeira dorsal com 15 espinhos e 14 raios flexíveis; mancha negra ovalada na base dos primeiros raios flexíveis da nadadeira dorsal . Tilapia rendalli (tilápia)

27' Perfil pré-dorsal reto ou ligeiramente côncavo; nadadeira dorsal com 17 espinhos e 13 raios flexíveis; mancha negra ovalada na base dos primeiros raios flexíveis da nadadeira dorsal ausente. Oreochromis niloticus (tilápia) 
28 Mandíbula (dentários) situada no mesmo nível da extremidade anterior da maxila (pré-maxilares) ou levemente posterior (boca terminal ou sub-terminal)

28' Mandíbula (dentários) estendendo-se anteriormente além do nível da extremidade anterior da maxila (pré-maxilares) (mandíbula prognata)

29 Olhos com margem orbital livre

Sternopygus macrurus (tuvira-preta)

29' Olhos completamente cobertos por pele Eigenmannia virescens (tuvira)

30 Corpo com padrão de bandas claras e escuras alternadas

30' Corpo com manchas irregulares dispersas pelo corpo Gymnotus sp. (tuvira)

31 Região lateral do corpo apresentado bandas claras e escuras alternadas com suas margens regulares

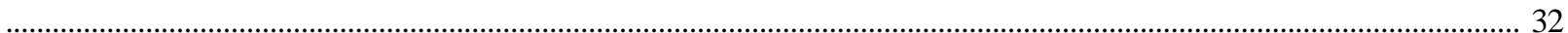

31' Região dorsal do corpo escura e porção ventro-lateral com bandas claras e escuras fragmentadas, formando um padrão de manchas irregulares Gymnotus cf. inaequilabiatus (tuvira)

32 Corpo com bandas escuras mais estreitas que as bandas claras Gymnotus cf. sylvius (tuvira)

32' Corpo com bandas claras mais estreitas que as bandas escuras Gymnotus cf. carapo (tuvira)

33 Corpo coberto por placas ósseas

34 Duas séries longitudinais de placas ósseas em cada lado do tronco; dois barbilhões em cada canto da boca; boca normal, sem aspecto de ventosa .

34' Várias séries longitudinais de placas ósseas em cada lado do tronco; um barbilhão em cada canto da boca; boca com aspecto de ventosa

35 Lábio inferior com um par de barbilhões; barbilhões maxilares não alcançando além da abertura branquial; mancha irregular escura na porção anterior do flanco Corydoras aeneus (limpa-fundo)

35' Lábio inferior sem barbilhões; barbilhões maxilares alcançando além da abertura branquial; flanco sem manchas. Callichthys callichthys (tamoatá)

36 Pedúnculo caudal deprimido, formando uma quilha de cada lado .........Rineloricaria pentamaculata (cascudo-lagartixa)

36' Pedúnculo caudal com seção transversal arredondada ou elíptica, sem formar quilhas laterais 37

37 Cintura escapular exposta, coberta com pequenos espinhos; adultos com porte pequeno (30 mm ou menos de comprimento padrão)

37' Cintura escapular não exposta, coberta com pele ou placas apenas; adultos com porte médio (50 mm ou mais de comprimento padrão)

38 Ponta do focinho com uma única placa rostral; linha lateral interrompida no meio do corpo.

38' Ponta do focinho com um par de placas rostrais; linha lateral contínua ao longo do corpo

Hisonotus sp. 1 (cascudinho)

Hisonotus sp. 2 (cascudinho)

39 Nadadeira adiposa presente; região ventral do tronco lisa ou com pequenas placas dispersas 40

39' Nadadeira adiposa ausente, ou pouco desenvolvida; região ventral do tronco com um único grande escudo (penta, hexa ou heptagonal) Neoplecostomus paranensis (cascudo)

40 Região ventral do tronco completamente coberta com placas; quilhas laterais no tronco presentes; olhos contidos cerca de 5,7 a 6,0 vezes na largura da cabeça e cerca de 2,7 a 2,9 vezes na largura interorbital; corpo com pintas pequenas circulares Hypostomus ancistroides (cascudo)

40' Região ventral do tronco nua ou parcialmente coberta com placas; quilhas laterais no tronco ausentes; olhos contidos cerca de 3,9 a 5,7 vezes na largura da cabeça e cerca de 1,6 a 2,3 vezes na largura interorbital; corpo sem pintas pequenas circulares 
41 Espinho da nadadeira peitoral expandido na porção terminal e com espinhos (odontódeos) hipertrofiados; corpo com grandes manchas irregulares, intercaladas por estreitas áreas claras ............. Hypostomus nigromaculatus (cascudo)

41' Espinho da nadadeira peitoral não expandido na porção terminal e com pequenos espinhos (odontódeos); corpo sem o padrão de grandes manchas irregulares difusas, intercaladas por estreitas áreas claras

Hypostomus regani (cascudo)

42 Corpo serpentiforme, uma única abertura branquial, mediana, localizada sob a cabeça; nadadeiras peitorais ausentes Synbranchus marmoratus (mussum)

42' Corpo não serpentiforme, um par de aberturas branquiais, localizada ao longo das regiões lateral e ventral da cabeça; nadadeiras peitorais presentes

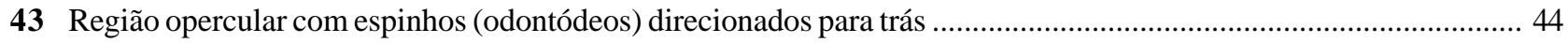

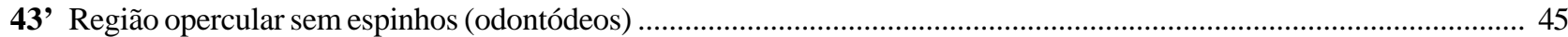

44 Nadadeiras pélvicas presentes

Trichomycterus sp. (cambeva, bagrinho)

44' Nadadeiras pélvicas ausentes Eremophilus sp. (cambeva, bagrinho)

45 Aberturas branquiais pequenas (membranas branquiais ligadas ao istmo); olhos laterais; corpo com máculas claras Tatia neivai (bagrinho)

45' Aberturas branquiais amplas (membranas branquiais livres do istmo); olhos dorsais ou dorso-laterais; corpo sem máculas claras.. . .46

46 Primeiro raio das nadadeiras dorsal e peitoral quase totalmente rígido, formando um espinho 47

46' Primeiro raio das nadadeiras dorsal e peitoral flexível em mais da metade de seu comprimento, não formando um espinho 49

47 Corpo com três ou quatro séries longitudinais bem definidas de máculas escuras arredondadas, com reflexos amarelos quando o peixe está vivo; processo ósseo do cleitro (acima da nadadeira peitoral) muito evidente, de formato triangular Pimelodus maculatus (mandi)

47' Corpo sem séries longitudinais de máculas, com coloração parda quando o peixe está vivo; processo ósseo do cleitro (acima da nadadeira peitoral), quando presente, afilado . 48

48 Tronco com coloração uniforme e com faixa escura conspícua ao longo da linha lateral; nadadeira caudal com lobos estreitos, de comprimento igual ou com o lobo superior levemente mais longo que o inferior; processo posterior do supra-occipital unido à nadadeira dorsal Pimelodella sp. (mandi-chorão)

48 Tronco com manchas irregulares e sem uma faixa escura conspícua ao longo da linha lateral; nadadeira caudal com lobos largos, com o lobo inferior levemente mais longo que o superior; processo posterior do supra-occipital não atingindo a nadadeira dorsal Rhamdia quelen (bagre, jundiá)

49 Dorso com barras transversais escuras; lobo caudal superior geralmente mais longo que o inferior ..... 50

49' Dorso sem barras transversais escuras; lobo caudal inferior geralmente mais longo que o superior 51

50 Corpo de coloração castanha escura; olhos pequenos, contidos cerca de 5,4 a 7,2 vezes no comprimento da cabeça, com a margem dorsal discreta; borda posterior das nadadeiras dorsal, peitoral, pélvica e anal arredondada..

Imparfinis mirini (bagrinho)

50' Corpo de coloração acinzentada; olhos grandes, contidos cerca de 4,8 a 5,3 vezes no comprimento da cabeça, com margem dorsal nitidamente invaginada; borda posterior das nadadeiras dorsal, peitoral e anal truncada ou levemente côncava ... Imparfinis schubarti (bagrinho)

51 Corpo curto e alto, altura do corpo contida cerca de 4,8 a 5,2 vezes no comprimento padrão; boca inferior; borda posterior das nadadeiras dorsal, peitoral, pélvica e anal truncada ou côncava ......................................................................................................... Cetopsorhamdia iheringi (bagrinho)

51' Corpo longo e baixo, altura do corpo contida cerca de 7,2 a 9,2 vezes no comprimento padrão; boca prognata (i.e. mandíbula projetada para frente); borda posterior das nadadeiras dorsal, peitoral, pélvica e anal convexa

Phenacorhamdia tenebrosa (bagrinho) 
7. Material das espécies de peixes coletadas nos riachos da bacia do Rio Paranapanema e tombadas na coleção ictiológica do LIRP-USP

Apareiodon piracicabae: LIRP 2553; Astyanax altiparanae: LIRP 2878, 2881, 2883, 2884, 2890, 2893, 2894, 2905, 2909, 2911, 2918; Astyanax fasciatus: LIRP 2754, 2755, 2756, 2759, 2768, 2771; Astyanax scabripinnis: LIRP 2722, 2723, 2725, 2730; Astyanax sp. 1: LIRP 2736, 2737, 2738, 2739, 2740, 2743, 2748; Astyanax sp. 2: LIRP 2734; Bryconamericus sp.: LIRP 2784, 2785, 2789; Bryconamericus stramineus: LIRP 2791, 2793, 2797, 2799; Callichthys callichthys: LIRP 2541, 2542; Cetopsorhamdia iheringi: LIRP 2805, 2807, 2809, 2811; Cichlasoma paranaense: LIRP 2605, 2608; Corydoras aeneus: LIRP 1700, 2544, 2552, 2553, 2555, 2559, 2560; Crenicichla britskii: LIRP 1705, 2576, 2583, 2585, 2586; Cyphocharax modestus: LIRP 2347; Characidium gomesi: LIRP 2507, 2508; Characidium zebra: LIRP 2513, 2514, 2518, 2526; Eigenmannia virescens: LIRP 2822, 2825; Eremophilus sp.: LIRP 2801; Geophagus brasiliensis: LIRP 2644, 2653, 2654, 2655, 2656; Gymnotus cf. carapo: LIRP 2857, 2859; Gymnotus cf. inaequilabiatus: LIRP 2860, 2861, 2862, 2863, 2865; Gymnotus sp.: LIRP 2866; Gymnotus cf. sylvius: LIRP 2832, 2836, 2839, 2841, 2844, 2845; Hisonotus sp. 1: LIRP 1703, 2260, 2261, 2267, 2268; Hisonotus sp. 2: LIRP 2262; Hoplias malabaricus: LIRP 1694, 2307, 2313, 2319, 2321, 2323; Hypostomus ancistroides: LIRP 1701, 2674, 2680, 2685 , 2686, 2688, 2690, 2697, 2699, 2700, 2703, 2709, 2710, 2711, 2712; Hypostomus nigromaculatus: LIRP 2657, LIRP 1702; Hypostomus regani: LIRP 2659, 2660, 2661; Imparfinis mirini: LIRP 1696, 2948, 2949, 2950, 2952, 2953, 2954, 2955, 2956, 2966; Imparfinis schubarti: LIRP 2937, 2939; Leporinus paranensis: LIRP 2254; Moenkhausia sanctaefilomenae: LIRP 2390; Neoplecostomus paranensis: LIRP 2778; Oligosarcus paranensis: LIRP 2394, 2395, 2396; Oligosarcus pintoi: LIRP 1695; Oreochromis niloticus: LIRP 2594; Phalloceros caudimaculatus: LIRP 1704, 2616, 2617, 2619, 2628, 2629; Phenacorhamdia tenebrosa: LIRP 1699, 2868, 2869, 2873, 2875; Piabina argentea: LIRP 2415, 2417, 2418, 2419, 2422; Pimelodella sp.: LIRP 1697, 2924, 2925, 2928, 2933; Pimelodus maculatus: LIRP 2392; Poecilia reticulata: LIRP 2635, 2641; Rhamdia quelen: LIRP 1698, 2437, 2444, 2445, 2452, 2457, 2460, 2461, 2462, 2464, 2465; Rineloricaria pentamaculata: LIRP 2777; Serrapinnus notomelas: LIRP 2500, 2504, 2505; Serrapinnus sp.: LIRP 2491; Sternopygus macrurus: LIRP 2813, 2815; Synbranchus marmoratus: LIRP 2571, 2573, 2575; Tatia neivai: LIRP 2413; Tilapia rendalli: LIRP 2592; Trichomycterus sp.: LIRP 2798, 2799, 2800.

\section{Agradecimentos}

Somos gratos a Jaqueline V. Bortolieiro pelo auxílio na digitação e organização dos dados no laboratório e a Sandra Raredon pelo auxílio na produção de radiografias digitais de algumas espécies; aos ictiólogos sistematas
Heraldo A. Britski, Marcelo R. Britto, Ricardo Campos-daPaz, Carlos A. A. Figueiredo, Julio C. Garavello, Francisco Langeani, Luiz R. Malabarba, Naércio A. Menezes, Osvaldo T. Oyakawa, Mario C. C. de Pinna, Richard P. Vari e Stanley H. Weitzman, pela ajuda na identificação dos grupos de peixes de suas respectivas áreas de especialidade; a Richard P. Vari e Naércio A. Menezes pela leitura e sugestões ao manuscrito; ao Instituto Brasileiro de Meio Ambiente e dos Recursos Naturais Renováveis (IBAMA), pela autorização de coleta e transporte de peixes concedida para a realização deste trabalho (autorização DIREN no 38/99, datada de 06.vii.1999); ao Neotropical Lowland Research Program of the International Sciences Program of the Smithsonian Institution, E.U.A., pelo auxílio financeiro e suporte durante as visitas técnicas do primeiro autor à Division of Fishes do National Museum of Natural History da mesma instituição; ao Research Training Program do National Museum of Natural History do Smithsonian Institution, por ter recebido ACR e MC e capacitado os mesmos a resolver importantes questões sistemáticas pertinentes a este trabalho; e finalmente, ao Departamento de Biologia da F.F.C.L.R.P. Universidade de São Paulo, pelo apoio oferecido durante a realização deste trabalho. Este trabalho foi financiado pela Fundação de Amparo à Pesquisa do Estado de São Paulo (FAPESP) dentro do Programa BIOTASP/FAPESP - O Instituto Virtual da Biodiversidade (www.biota.org.br) através do Projeto Temático "Diversidade de peixes de riachos e cabeceiras da bacia do Alto Rio Paraná no Estado de São Paulo, Brasil/Fish diversity of the headwaters and streams of the upper Paraná River system in the State of São Paulo, Brazill" (FAPESP n ${ }^{\circ}$ 98/05072-8) e também pelo Projeto PRONEX "Conhecimento, Conservação e Utilização Racional da Diversidade da Fauna de Peixes do Brasil" (FINEP/CNPq n 661058/1997-2). RMCC é bolsista de pesquisa (CNPq n ${ }^{\circ}$ 301309/1991-4); LC é jovem pesquisadora (FAPESP n ${ }^{\text {os }} 01 / 13340-7$ e 02/05996-2), foi bolsista de pósdoutoramento (FAPESP no 00/01919-8) e doutoramento (FAPESP n ${ }^{\circ}$ 96/03286-5); KMF, RCB, GZPD, TXA, FZG e FCTL são bolsistas doutoramento (FAPESP n ${ }^{\text {os }}$ 02/05464-0; 00/01920-6; 01/00780-9; 98/12552-6; 00/06722-8 e 01/144492); KMF, ALAM e FCTL foram bolsistas de mestrado (FAPESP n ${ }^{\text {os }}$ 00/01918-1; 99/03852-9 e 99/02402-0); MC é bolsista de iniciação científica (FAPESP n ${ }^{\circ}$ 02/00873-0); e RS foi bolsista de capacitação técnica (nível I) e de iniciação científica (FAPESP n ${ }^{\text {os }}$ 98/5072-8 e 00/14030-9).

Finalmente, gostaríamos de agradecer, sem exceção, a todos os proprietários das terras onde localizam-se os trechos de riachos visitados - cujo o espectro de variação de nível educacional e afluência financeira era extremamente amplo - pelo total, irrestrito ,e até mesmo muitas vezes caloroso, apoio recebido, sem o qual este trabalho não teria sido possível. 


\section{Referências Bibliográficas}

AB'SABER, A.N. 1956. Relevo, estrutura e rede hidrográfica do Brasil. Bol. Geográfico 14:225-268.

AB'SABER, A.N. 1977a. Os domínios morfoclimáticos da América do Sul. Geomorfologia 52:1-21.

AB'SABER, A.N. 1977b. Potencialidades paisagísticas brasileiras. Geomorfologia 55:1-27.

AGOSTINHO, A.A. \& JÚLIO Jr., H.F. 1999. Peixes da bacia do Alto rio Paraná. In Estudos ecológicos de comunidades de peixes tropicais (A.E.A.M. Vazzoler, A.A. Agostinho \& P.T. Cunningham, eds.). EDUSP, São Paulo, p. 374-400.

AMARAL, M.F., ARANHA, J.M.R. \& MENEZES, M.S. 1998. Reproduction of the freshwater catfish Pimelodella pappenheimi in Southern Brazil. Stud. Neotr. Fauna and Environ. 33:106-110.

ARANHA, J.M.R., CARAMASCHI, E.P. \& CARAMASCHI, U. 1993. Ocupação espacial, alimentação e época reprodutiva de duas espécies de Corydoras Lacépède (Siluroidei, Callichthyidae) coexistentes no rio Alambari (Botucatu, São Paulo). Revta. bras. Zool. 10:453-466.

ARANHA, J.M.R., TAKEUTI, D.F. \& YOSHIMURA, T.M. 1998. Habitat use and food partitioning of the fishes in a coastal stream of Atlantic Forest, Brazil. Rev. Biol. Trop. 46:951-959.

ARAÚJO-LIMA, C.A.R.M., AGOSTINHO, A.A. \& FABRÉ, N.F. 1995. Trophic aspects of fish communities in brazilian rivers and reservoirs. In Limnology in Brazil (J.G. Tundisi, C.E.M. Bicudo \& T.M. Tundisi, eds.). Academia Brasileira de Ciências e Sociedade Brasileira de Limnologia, Rio de Janeiro, p. 105-136.

BARRETO, M.G. \& UIEDA, V.S.. 1998. Influence of the abiotic factors on the ichthyofauna composition in different orders stretches of Capivara River, São Paulo State, Brazil. Verh. Internat. Verein. Limnol., 26: 2180-2183.

BERRA, T.M. 2001. Freshwater fish distribution. Academic Press, San Diego, 604 p.

BIZERRIL, C.R.S.F. 1994. Análise taxonômica e biogeográfica da ictiofauna de água doce do leste brasileiro. Acta Biol. Leopoldensia 16:51-80.

BÖHLKE, J., WEITZMANN, S.H. \& MENEZES, N.A. 1978. Estado atual da sistemática de peixes de água doce da América do Sul. Acta Amaz. 8:657-677.

BRITSKI, H.A. \& LANGEANI, F. 1988. Pimelodus paranaensis, sp. n., um novo Pimelodidae (Pisces, Siluriformes) do Alto Paraná, Brasil. Revta Bras. Zool. 5:409-417.

BROWER, J.E. \& ZAR, J.H. 1984. Field and laboratory methods for general ecology. Wm. C. Brown Publishers, Dubuque, $226 \mathrm{p}$.
CARVALHO, E.D., DA SILVA, V.F.B., FUGIHARA, C.Y., HENRY, R. \& FORESTI, F. 1998. Diversity of fish species in the River Paranapanema Jurumirim Reservoir transition region (São Paulo, Brazil). Italian J. Zool. 65:325-330.

CASATTI, L. 2002. Alimentação dos peixes em um riacho do Parque Estadual Morro do Diabo, bacia do Alto Rio Paraná, Sudeste do Brasil. Biota Neotropica 2(2): 1-14.

CASATTI, L. \& CASTRO, R.M.C. 1998. A fish community of the São Francisco River headwaters riffles, southeastern Brazil. Ichthyol. Explor. Freshwaters 9:229-242.

CASATTI, L., LANGEANI, F. \& CASTRO, R.M.C. 2001. Peixes de riacho do Parque Estadual Morro do Diabo, bacia do Alto Rio Paraná, SP. Biota Neotropica 1(1/2):115.

CASTRO, R.M.C. 1999. Evolução da ictiofauna de riachos sul-americanos: padrões gerais e possíveis processos causais. In Ecologia de Peixes de Riachos: Estado Atual e Perspectivas (E.P. Caramaschi, R. Mazzoni, C.R.S.F. Bizerril, P.R. Peres-Neto, eds.). Oecologia Brasiliensis, v. VI, Rio de Janeiro, p. 139-155.

CASTRO, R.M.C. \& CASATTI, L. 1997. The fish fauna from a small forest stream of the upper Paraná River Basin, southeastern Brazil. Ichthyol. Explor. Freshwaters 7:337352.

CASTRO, R.M.C. \& MENEZES, N.A. 1998. Estudo diagnóstico da diversidade de peixes do Estado de São Paulo. In Biodiversidade do Estado de São Paulo, Brasil: síntese do conhecimento ao final do século XX, vol. 6 Vertebrados (R.M.C. Castro, ed., C.A. Joly \& C.E.M. Bicudo, orgs.). WinnerGraph - FAPESP, São Paulo, p. 113.

COLWELL, R.K. 1997. EstimateS 5. Statistical estimation of species richness and shared species from samples. Version 5.0.1 (URL: http://viceroy.eeb.uconn.edu/estimates, 08.ix.2001), University of Connecticut.

COSTA, W. J.E.M., 1984, Peixes fluviais do sistema lagunar de Maricá, Rio de Janeiro, Brasil. Rev. Atlântica 7: 65-82.

ESTEVES, K.E. \& ARANHA, J.M.R. 1999. Ecologia trófica de peixes de riachos. In Ecologia de Peixes de Riachos: Estado Atual e Perspectivas (E.P. Caramaschi, R. Mazzoni, C.R.S.F. Bizerril, P.R. Peres-Neto, eds.). Oecologia Brasiliensis, v. VI, Rio de Janeiro, p. 157-182.

GARUTTI, V. 1988. Distribuição longitudinal da ictiofauna de um córrego na região noroeste do Estado de São Paulo, Bacia do Rio Paraná. Rev. Bras. Biol. 48:747-759.

GÉRY, J. 1969. The fresh-water fishes of South America. In Biogeography and ecology in South America, vol. 2 (E. J. Fittkau et al., eds.). Junk, The Hague, p. 828-848.

HENRY, R., UIEDA, V.S., AFONSO, A.A.O. \& KIKUCHI, R.M. 1994. Input of allochthonous matter and structure of fauna in a Brazilian headstream. Verh. Internat. Verein. Limnol. 25:1866-1870. 
HUECK, K. \& SEIBERT, P. 1981. Vegetationskarte von Südamerika. Band IIa. Fischer, Sttutgart, 90 p.

INSTITUTO GEOGRÁFICO E GEOLÓGICO. 1974. Mapa Geológico do Estado de São Paulo. Secretaria de Estado dos Negócios da Agricultura, Coordenadoria de Pesquisa de Recursos Naturais.

INVENTÁRIOFLORESTALDOESTADODESÃO PAULO. 1993. Instituto Florestal, Governo do Estado de São Paulo e Secretaria do Meio Ambiente, São Paulo, 199 p.

JACOBO, M.A.C. \& VERON, M.C.B. 1995. Relaciones troficas de la ictiofauna de cuencas autoctonas del Chaco Oriental, Argentina. Rev. Brasil. Biol. 55:419-437.

LANGEANI, F. 1990. Revisão do gênero Neoplecostomus Eigenmann \& Eigenmann, 1888, com a descrição de quatro novas espécies do Sudeste brasileiro (Ostariophysi, Siluriformes, Loricariidae). Comun. Mus. Ciênc. PUCRS, Sér. Zool. 3:3-31.

LEE, S.M. \& CHAO, A. 1994. Estimating population size via sample coverage for closed capture-recapture models. Biometrics 50:88-97.

LOWE-McCONNELL, R.H. 1975. Fish communities in tropical freshwaters: their distribution, ecology and evolution. Longman, New York, 337 p.

LOWE-McCONNELL, R.H. 1987. Ecological studies in tropical fish communities. Cambridge Univ. Press, Cambridge, $382 \mathrm{p}$.

LOWE-McCONNELL, R.H. 1999. Estudos ecológicos de comunidades de peixes tropicais. Editora da Universidade de São Paulo, São Paulo, Brasil, 534 p.

LUDWIG, J.A. \& REYNOLDS, J.F. 1988. Statistical Ecology: a primer on methods and computing. John Wiley \& Sons, New York, $337 \mathrm{p}$.

MALABARBA, L.R. \& REIS, R.E. 1987. Manual de técnicas para a preparação de coleções zoológicas. Sociedade Brasileira de Zoologia (Campinas) 36:1-14.

MATTHEWS, W.J. 1998. Patterns in freshwater fish ecology. Chapman \& Hall, Norwell, Massachusetts, 756 p.

MAZZONI, R., FENERICH-VERANI, N. \& CARAMASCHI, E.P. 2000. Electrofishing as a sampling technique for coastal stream fish populations and communities in the southeast of Brazil. Rev. Brasil. Biol. 60:205-216.

MAZZONI, R. \& LOBÓN-CERVIÁ, J. 2000. Longitudinal structure, density and production rates of a Neotropical stream fish assemblage: the river Ubatiba in the Serra do Mar (South-East Brazil). Ecography 23: 588-602.

McALECEE, N., LAMBSHEAD, P.J.D., PATERSON, G.L.J. \& GAGE, J.D. 1997. BioDiversity Professional. Beta-Version. The Natural History Museum and The Scottish Association for Marine Sciences.
MENEZES, N.A. 1988. Implication of the distribution patterns of the species of Oligosarcus (Teleostei, Characidae) from central and southern South America. In Proceedings of a Workshop on Neotropical Distribution Patterns (P.E. Vanzolini \& W.R. Heyer, eds.). Academia Brasileira de Ciências, Rio de Janeiro, p. 295304.

MENEZES, N.A. 1996a. Conservação da diversidade da ictiofauna da Bacia Paraná-Paraguai-Uruguai. Anais XV Congresso Panamericano de Ciências Veterinárias, Campo Grande, MS, 4 p.

MENEZES, N.A. 1996b. Methods for assessing freshwater fish diversity. In Biodiversity in Brazil (C.E.M. Bicudo \& N.A. Menezes, eds.). CNPq, São Paulo, p. 289-312.

MENEZES, N.A., CASTRO, R.M.C., WEITZMAN, S.H. \& WEITZMAN, M.J. 1990. Peixes de riacho da Floresta Atlântica Costeira Brasileira: um conjunto pouco conhecido e ameaçado de vertebrados. In II Simpósio de Ecossistemas da Costa Sul e Sudeste Brasileira: Estrutura, Função e Manejo. Academia de Ciências do Estado de São Paulo, vol. 1, p. 290-295.

NIMER, E. 1989. Climatologia do Brasil. Secretaria de Planejamento e Coordenação da Presidência da República e IBGE, Rio de Janeiro, Brasil, 421 p.

PAVANELLI, C.S. \& CARAMASCHI, E.P. 1997. Composition of the ichthyofauna of two small tributaries of the Paraná river, Porto Rico, Paraná State, Brazil. Ichthyol. Explor. Freshwaters 8:23-31.

PENCZAK, T., AGOSTINHO, A.A. \& OKADA, E.K. 1994. Fish diversity and community structure in two small tributaries of the Paraná River, Paraná State, Brazil. Hydrobiol. 294:243-251.

PESQUISA FAPESP. 2001. Censo científico. Fundação de Amparo à Pesquisa do Estado de São Paulo, São Paulo, Brasil, 62:18-19.

REYNOLDS, J.B. 1992. Electrofishing. In Fisheries Techniques (L.A. Nielsen \& D.L. Johnson, eds.). American Fisheries Society, Bethesda, p. 147-163.

RIZZINI, C.T. 1997. Tratado de fitogeografia do Brasil: aspectos ecológicos, sociológicos e florísticos: segunda edição. Âmbito Cultural Edições, Rio de Janeiro, Brasil, $747 \mathrm{p}$.

SABINO, J. \& CASTRO, R.M.C. 1990. Alimentação, período de atividade e distribuição espacial dos peixes de um riacho da floresta Atlântica (sudeste do Brasil). Rev. Brasil. Biol. 50:23-36.

SABINO, J. \& ZUANON, J.A. 1998. A stream fish assemblage in Central Amazonia: distribution, activity patterns and feeding behavior. Ichthyol. Explor. Freswaters 8:201210. 
SAMPAIO, T. 1944. Relatório dos rios Itapetininga e Paranapanema. Rev. Inst. Geogr. Geol. 2(3):222-271.

SAZIMA, I. 1986. Similarities in feeding behaviour between some marine and freshwater fishes in two tropical communities. J. Fish. Biol. 29:53-65.

SEVERI, W., HICKSON, R.G. \& MARANHÃO, T.C.F. 1995. Use of electric fishing for fish fauna survey in Southern Brazil. Rev. Brasil. Biol. 55:651-660.

SOARES, M.G.M. 1979. Aspectos ecológicos (alimentação e reprodução) dos peixes do Igarapé do Porto, Aripuanã, MT. Acta Amazonica 9:325-352.

SOARES-PORTO, L.M. 1994. Dieta e ciclo diurno de atividade alimentar de Pimelodella lateristriga (Müller e Troschel, 1849) (Siluroidei, Pimelodidae) no rio Ubatiba, Maricá, Rio de Janeiro. Rev. Brasil. Biol. 54:451-458.

STRAHLER, A.N. 1957. Quantitative analysis of watershed geomorphology. Trans. Amer. Geoph. Union 38:913-920.

SUZUKI, H.I., PAVANELLI, C.S., FUGI, R., BINI, L.M. \& AGOSTINHO, A.A. 1997. Ictiofauna de quatro tributários do reservatório de Segredo. In Reservatório de Segredo: bases ecológicas para o manejo (A.A. Agostinho \& L.C. Gomes, eds.). EDUEM, Maringá, p. 259-273.

UIEDA, V.S. 1984. Ocorrência e distribuição dos peixes em um riacho de água doce. Rev. Brasil. Biol. 2:203-213.

UIEDA, V.S. \& BARRETO, M.G. 1999. Composição da ictiofauna de quatro trechos de diferentes ordens do rio Capivara, bacia do Tietê, Botucatu, São Paulo. Rev. Bras. Zoociências, 1(1): 55-67.

UIEDA, V.S., BUZZATO, P. \& KIKUCHI, R.M. 1997. Partilha de recursos alimentares em peixes em um riacho de serra no Sudeste do Brasil. An. Acad. Bras. Ci. 69:243-252.

UIEDA, V.S. \& UIEDA, W. 2001. Species composition and spatial distribution of a stream fish assemblage in the east coast of Brazil: comparison of two field study methodologies. Braz. J. Biol., 61(3): 377-388.

VANZOLINI, P.E. \& PAPAVERO, N. 1967. Manual de coleta e preparação de animais terrestres e de água doce. Fonseca LTDA, Departamento de Zoologia - Secretaria da Agricultura do Estado de São Paulo, 223 p.

VARI, R.P. 1988. The Curimatidae, a lowland Neotropical fish family (Pisces: Characiformes); distribution, endemism, and phylogenetic biogeography. In Proceedings of a Workshop on Neotropical Distribution Patterns (P.E. Vanzolini \& W.R. Heyer, eds.). Academia Brasileira de Ciências, Rio de Janeiro, p. 343-377.
WEITZMAN, S.H., MENEZES, N.A. \& WEITZMAN, M.J. 1988. Phylogenetic biogeography of the Glandulocaudinae (Teleostei: Characiformes, Characidae) with comments on distribution of the other freshwater fishes in eastern and southeastern Brazil. In Proceedings of a Workshop on Neotropical Distribution Patterns (P.E. Vanzolini \& W.R. Heyer, eds.). Academia Brasileira de Ciências, Rio de Janeiro, p. 379-427.

WISCHNATH, L. 1993. Atlas of livebearers of the world. T.H.F. Publications, Neptune City, 336 p.

ZIESLER, R. \& ARDIZZONE, G.D. 1979. The inland waters of Latin America. Copescal Technical Paper No. 1. Food and Agriculture Organization of the United Nations (FAO), Roma, $171 \mathrm{p}$.

Título: Estrutura e composição da ictiofauna de riachos do Rio Paranapanema, sudeste e sul do Brasil

Autores: Ricardo M. C. Castro; Lilian Casatti; Hertz F. Santos; Katiane M. Ferreira; Alexandre C. Ribeiro; Ricardo C. Benine; Gabriela Z. P. Dardis; Alex L. A. Melo; Renata Stopiglia; Tatiana X. Abreu; Flávio A. Bockmann; Murilo Carvalho; Fernando Z. Gibran \& Flávio C. T. Lima

Biota Neotropica, Vol. 3 ( número 1): 2003

http://www.biotaneotropica.org.br/v3n 1/pt/ abstract?article+BN01703012003

Recebido em: 18/02/2003

Publicado em: 11/04/2003

ISSN 1676-0603 